\title{
Which ocean colour algorithm for MERIS in North West European waters?
}

\author{
Gavin Tilstone a,*, Silvana Mallor-Hoya ${ }^{\mathrm{a}}$, Francis Gohin ${ }^{\mathrm{b}}$, André Belo Couto ${ }^{\mathrm{c}}$, Carolina Sá ${ }^{\mathrm{c}}$, Priscila Goela ${ }^{\mathrm{d}, \mathrm{e}}$, \\ Sónia Cristina ${ }^{\mathrm{d}, \mathrm{e}}$, Ruth Airs ${ }^{\mathrm{a}}$, John Icely ${ }^{\mathrm{d}, \mathrm{e}}$, Marco Zühlke ${ }^{\mathrm{f}}$, Steve Groom ${ }^{\mathrm{a}}$ \\ a PML-Plymouth Marine Laboratory, Prospect Place, The Hoe, Plymouth PL1 3DH, UK \\ b IFREMER, Laboratoire d'écologie pélagique, DYNECO PELAGOS, BP 70, 29280 Plouzané, France \\ ' MARE-Marine and Environmental Sciences Centre, Faculdade de Ciências da Universidade de Lisboa, Campo Grande, 1749-016 Lisboa, Portugal \\ d CIMA-Centro de Investigação Marinha e Ambiental, FCT, Universidade do Algarve, Campus de Gambelas, 8005-139 Faro, Portugal \\ e SAGREMARISCO Lda, Apartado 21, 8650-999 Vila do Bispo, Portugal \\ ${ }^{\mathrm{f}}$ Brockmann Consult, Max-Planck-Str. 2, 21502 Geesthacht, Germany
}

\section{A R T I C L E I N F O}

\section{Article history:}

Received 26 November 2015

Received in revised form 1 November 2016

Accepted 15 November 2016

Available online $\mathrm{xxxx}$

\section{Keywords:}

Case 2 waters

Coastal waters

Shelf waters

Chlorophyll- $a$

North Sea

Ocean colour

Remote sensing

MERIS

English Channel

Mediterranean coast

Portuguese coast

\begin{abstract}
A B S T R A C T
Chlorophyll- $a(\mathrm{Chl} a)$ is a key parameter for the assessment of water quality in coastal and shelf environments. The availability of satellite ocean colour offers the potential of monitoring these regions at unprecedented spatial and temporal scales, as long as a high level of accuracy can be achieved. To use satellite derived Chl $a$ to monitor these environments, it is imperative that rigorous accuracy assessments are undertaken to select the most accurate ocean colour algorithm(s).

To this end, the accuracy of a range of ocean colour Chl $a$ algorithms for use with Medium Imaging Resolution Spectrometer (MERIS) Level 2 (L2) Remote Sensing Reflectance $\left(R_{r S}\right)$, using two different atmospheric correction (AC) processors (COASTCOLOUR and MERIS Ground Segment processor version 8.0 - MEGS8.0), were assessed in North West European waters. A total of 594 measurements of $R_{r s}(\lambda)$ and/or Chl $a$ were made in the North Sea, Mediterranean Sea, along the Portuguese Coast, English Channel and Celtic Sea between June 2001 and March 2012, where Chl $a$ varied from 0.2 to $35 \mathrm{mg} \mathrm{m}^{-3}$. The following algorithms were compared: MERIS Case 1 water Chl $a$ algorithm OC4Me, the MERIS Case 2 algorithm Algal Pigment 2 (AP2), the MODIS-Aqua Case 1 Chl $a$ algorithm OC3 adapted for MERIS (OC3Me), the MODIS-Aqua Garver-Siegel-Maritorena algorithm (GSM) adapted for MERIS and the Gohin et al. (2002) algorithm for MERIS (OC5Me). For both COASTCOLOUR and MEGS8.0 processors, OC5Me was the most accurate Chl $a$ algorithm, which was within $~ 25 \%$ of in situ values in these coastal and shelf waters. The uncertainty in MEGS8.0 $R_{r s}(442)(\sim 17 \%)$ was slightly higher compared to COASTCOLOUR ( 12\%) from 0.3 to $7 \mathrm{mg} \mathrm{m}^{-3} \mathrm{Chl} a$, but for $R_{r s}(560)$ the uncertainty was lower for MEGS8.0 $(\sim 10 \%)$ compared to COASTCOLOUR $(\sim 13 \%)$, which meant that MEGS8.0 Chl $a$ was more accurate than COASTCOLOUR for all of the Chl $a$ algorithms tested. Compared to OC5Me, OC4Me tended to over-estimate Chl $a$, which was caused by non-algal SPM especially at values $>14 \mathrm{~g} \mathrm{~m}^{-3}$. GSM also over-estimated Chl $a$, which was caused by variations in absorption coefficient of coloured dissolved organic matter at $442 \mathrm{~nm}$ $\left(a_{\text {СDOM }}(442)\right)$. AP2 consistently under-estimated $\mathrm{Chl} a$, especially when non-algal SPM was $>4 \mathrm{~g} \mathrm{~m}^{-3}$.
\end{abstract}

Crown Copyright @ 2016 Published by Elsevier Inc. All rights reserved.

\section{Introduction}

Information on marine environmental parameters, such as chlorophyll- $a(\mathrm{Chl} a)$, is fundamental for monitoring water quality, eutrophication and climate change (Birk et al., 2012; Boyce et al., 2010; Ferreira et al., 2011). Large scale spatial and temporal information on these parameters can be obtained by means of satellite remote sensing, which can aid our understanding of biogeochemical cycles (Chang et al., 2015; Siegel et al., 2014).

\footnotetext{
* Corresponding author.

E-mail address: ghti@pml.ac.uk (G. Tilstone).
}

Monitoring the water quality of coastal and shelf waters is an integral part of water resource management, which allows tracking the effects of anthropogenic pollutants in the marine environment. Through the Urban Waste Water Treatment, Nitrate and Water Framework Directives, the European Union provided a general definition of 'good ecological status' for coastal waters based on 19 key parameters, which includes microbiological and physico-chemical variables. One of these parameters is Chl $a$, which is the photo-synthetically active pigment of phytoplankton, and can be measured indirectly from satellite ocean colour. In open ocean waters, a range of satellite ocean colour products have been developed, which have proven successful in areas where the principal optically active material in the water column is 
phytoplankton. It is however, more difficult to accurately determine Chl $a$ from satellite in optically complex coastal and shelf regions (IOCCG, 2000 ). Coastal areas only account for $~ 7 \%$ of the world ocean's surface, yet play a globally important role in ameliorating human impacts on the marine ecosystem. Anthropogenic discharge of nutrients is advantageous for micro-phytoplankton such as diatoms and dinoflagellates, which potentially could result in increases in planktonic food web productivity in global coastal and shelf zones, and in turn may enhance annual carbon sequestration in marginal seas (Calbet et al., 2014). Coastal and shelf areas of Europe are commercially important for fishing and tourism, yet are subject to the increasingly adverse effects of harmful algal blooms (Baez et al., 2014; Glibert et al., 2014), eutrophication (Grizzetti et al., 2012; Romero et al., 2013) and climate change (Andersson et al., 2013; McQuatters-Gollop et al., 2007). In these regions, the presence of $a_{C D O M}$ and mineral SPM as well as Chl $a$ modify the light field (IOCCG, 2000), which makes accurate estimation of Chl $a$ from satellite data in these regions, difficult. It is therefore necessary to develop and validate the accuracy of $\mathrm{Chl} a$ algorithms in coastal and shelf regions to facilitate monitoring of these environments.

The availability of data from the satellite sensor MERIS (2002 - 2012), which had more spectral bands and a higher spatial resolution compared to SeaWiFS (1997-2010) plus novel atmospheric correction (AC) models, has enabled the development of new products for optically complex waters. These include an algorithm that retrieves inherent optical properties (IOP) and biogeochemical parameters from Case 2 waters (Doerffer and Schiller, 2007). Directional water leaving radiance is input to the algorithm and it outputs Chl $a$, SPM and the absorption coefficient of detrital material and gelbstoff $\left(a_{d g}\right)$ based on the conversion of scattering and absorption coefficients using non-linear multiple inversion solutions and regional conversion factors to give concentrations. This algorithm has been shown to be accurate in some (Doerffer and Schiller, 2007; Schiller and Doerffer, 2005), but not all Case 2 coastal (Cui et al., 2014; Melin et al., 2007; Tilstone et al., 2012), estuarine (Ambarwulan et al., 2010), freshwater lakes (Binding et al., 2011; Palmer et al., 2015) and other highly absorbing water bodies (Beltran-Abaunza et al., 2014; Folkestad et al., 2007; Ohde et al., 2007). As a consequence, a number of alternative algorithms have been proposed (Beltran-Abaunza et al., 2014; Hokedal et al., 2005; Peters et al., 2005; Tilstone et al., 2012; van der Woerd and Pasterkamp, 2004; Zibordi et al., 2009a). To improve satellite ocean colour algorithms, it is fundamental to improve the accuracy satellite $R_{r s}$ that are used to calculate Chl $a$. To this end, ESA funded a number of initiatives to improve the AC scheme for MERIS which included improvements in the neural network (NN) AC model for coastal waters (COASTCOLOUR), and re-processing of the MERIS archive using the MEGS8.0 processor which uses both a bright pixel correction for highly scattering waters and a clear water AC model (Lerebourg et al., 2011). It is important to test these and to select the most accurate algorithm for remotely sensed Chl $a$ in European coastal and shelf seas to coincide with the launch of the Copernicus new generation satellite Sentinel-3 (Donlon et al., 2012).

In this paper we validate a range of MERIS Chl $a$ products, using both MEGS8.0 and COASTCOLOUR processors, for the North West European regions of the North Sea, Celtic Sea, English Channel, South and Western Iberian Peninsula and Mediteranean Sea. Five ocean colour algorithms were compared and the choice of the algorithms was based on their availability to the user community as standard products for MERIS and MODIS-Aqua.

\section{Methods}

\subsection{Study area characteristics and sampling regime}

Remote Sensing Reflectance $\left(R_{r s}(\lambda)\right)$ and/or Chl $a$ were measured at 594 stations between April 2001 and March 2012 in the North Sea, English Channel and Celtic Sea (in the figures English Channel also refers to the Celtic Sea), Mediterranean Sea and along the Iberian coast (Fig. 1A). These data are available from ESA's MERMAID and COASTCOLOUR data sets (Nechad et al., 2015).

The North Sea is characterized by the entrance of warm, high saline water through the Orkney-Shetland inflow (off NE Scotland) and through the English Channel-Straits of Dover in the south (Fig. 1A), which drives a cyclonic pattern of circulation, which can cause re-suspension of sediment over the shallow North Sea shelf (Reid et al., 1988). The Portuguese coast is affected by seasonal upwelling from March to September and the poleward current during the winter months (Fiuza et al., 1982). In addition, the coastal waters close to Lisbon are strongly affected by the River Tagus, which elevates the CDOM and SPM on the shelf break (Valente and Da Silva, 2009). The Mediterranean Sea stations are in the central Ligurian Sea which is characterized by a cyclonic circulation that causes strong flows close to the coast which circulate north of the Island of Corsica and return in a south west direction (Fig. 1A) to establish a front between the coastal shelf and the deeper offshore water (Antoine et al., 2008).

North Sea and English Channel coastal areas have high absorption and scattering properties (Hommersom et al., 2009), which are optically variable due to different regional and seasonal contributions of $a_{C D O M}$, absorption coefficient of non-algal particles $\left(a_{N A P}\right)$ and particulate backscattering coefficient (Babin et al., 2003a; Babin et al., 2003b) and can therefore switch between case 1 and 2 water types (Groom et al., 2009). There are three main groups of specific-absorption properties in the North Sea, English Channel and Celtic Sea with low Chl a specific absorption coefficient of phytoplankton $\left(a_{p h}{ }^{*}\right)\left(<0.03 \mathrm{mg} \mathrm{m}^{-2}\right)$, high SPM specific absorption coefficient of non-algal particles $\left(a_{N A P}{ }^{*}\right)$ $\left(>0.04 \mathrm{~g} \mathrm{~m}^{-2}\right)$ and $a_{C D O M}\left(>0.4 \mathrm{~m}^{-1}\right)$ close to the coast; medium $a_{p h}{ }^{*}$ (>0.03, <0.05 mg m$\left.{ }^{-2}\right), a_{\text {NAP }}{ }^{*}\left(>0.02,<0.04 \mathrm{~g} \mathrm{~m}^{-2}\right)$ and $a_{\text {CDOM }}(>0.1$, $\left.<0.4 \mathrm{~m}^{-1}\right)$ over the shelf; and high $a_{p h}{ }^{*}\left(>0.05 \mathrm{mg} \mathrm{m}^{-2}\right)$, low $a_{N A P}{ }^{*}$ $\left(<0.02 \mathrm{~g} \mathrm{~m}^{-2}\right)$ and $a_{C D O M}\left(<0.1 \mathrm{~m}^{-1}\right)$ further offshore (Tilstone et al., 2012). Portuguese coastal waters are dominated by $a_{p h}$, though $a_{C D O M}$ can account for between 33 and $60 \%$ of the total absorption between bloom and non-bloom conditions (Goela et al., 2015). The principal satellite validation station in the Mediterranean Sea is BOUSSOLE, which is a deep clear water site where the dominant optically substance is phytoplankton. Other stations are sampled closer to the coast on the monthly transect to BOUSSOLE, which can be affected by other optically active substances (Antoine et al., 2008).

\subsection{Measurement of normalized water leaving radiance and Remote Sens- ing Reflectance}

Measurements of normalized water leaving radiance $\left(n L_{w}\right)$ were performed by the Royal Belgian Institute of Natural Sciences (RBINS), Centre for Marine and Environmental Research (CIMA) and Laboratoire d'Oceanographie de Villefranche (LOV). RBINS used three TriOS-RAMSES hyperspectral spectro-radiometers, two measuring radiance and one measuring downwelling irradiance, mounted on a steel frame fixed to the bow of the ship, facing forward to minimize ship shadow and reflection, so that zenith angles of the sea and sky viewing radiance sensors were $40^{\circ}$ as in (Ruddick et al. (2006). To reduce sun glint and bidirectional reflectance effects, the ship was maneuvered on station to point the radiance sensors at a relative azimuth angle of $135^{\circ}$ away from the sun. The spectro-radiometers were calibrated before and after the cruise consistent with SeaWiFS protocols (Mueller, 2000). Water-leaving reflectance $\left(\rho_{w}\right)$ was calculated from simultaneous above-water measurements of downwelling irradiance $\left(E_{d}^{0+}\right)$, total upwelling radiance $\left(L_{\text {sea }}^{0+}\right)$ and sky radiance $\left(L_{\text {sky }}^{0+}\right)$ (in the direction of the region of sky that reflects into the sea viewing sensor), from:

$\rho_{w}(\lambda)=\pi \frac{L_{\text {sea }}^{0+}(\lambda)-\rho_{\text {sky }} L_{\text {sky }}^{0+}(\lambda)}{E_{d}^{0+}(\lambda)}$ 


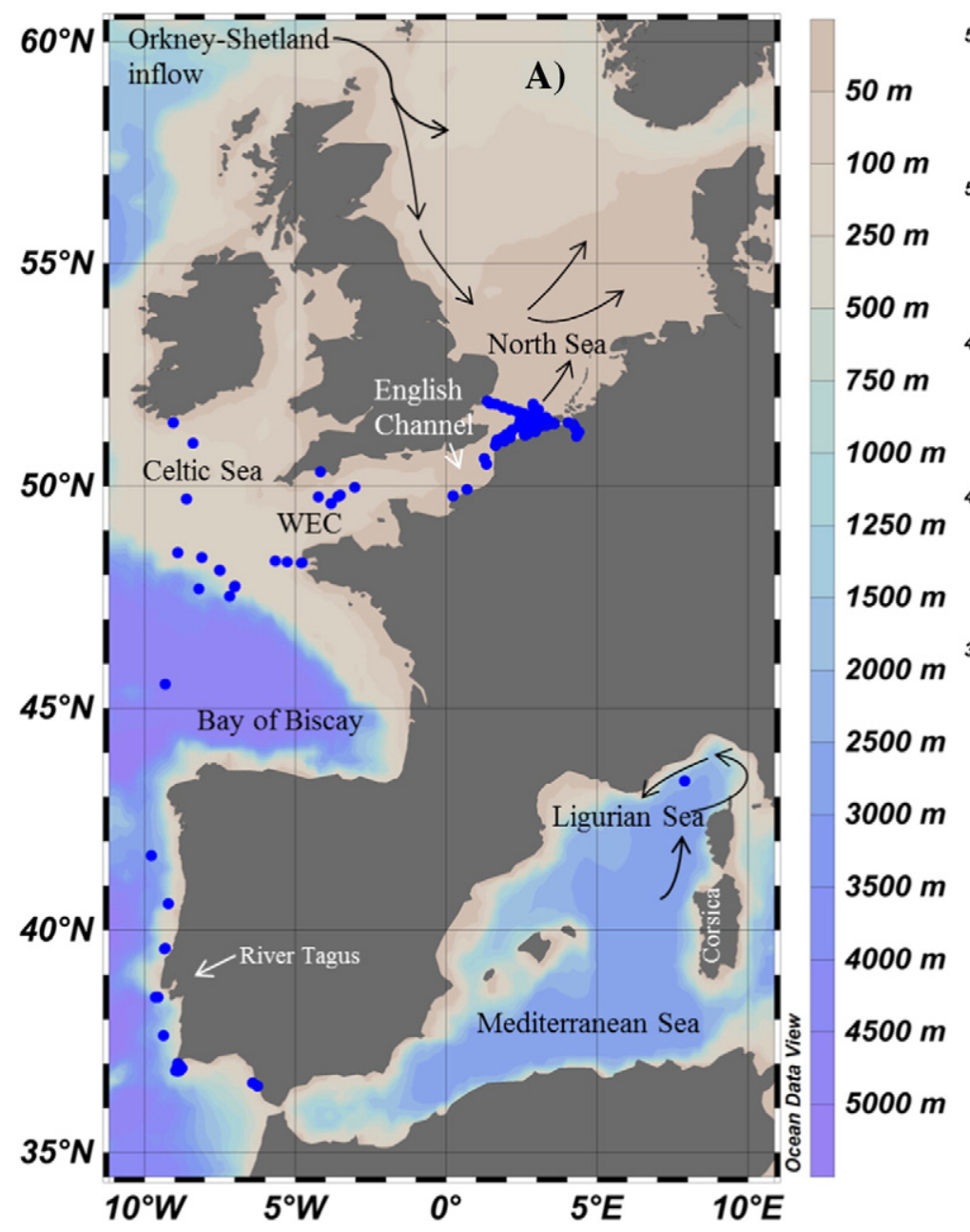

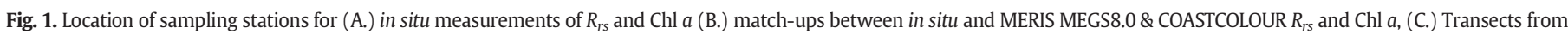

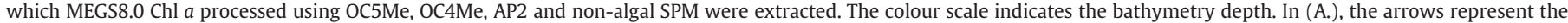

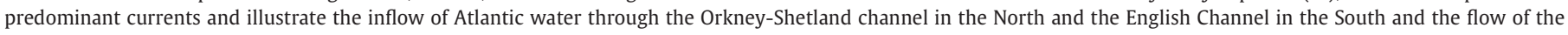
Mediterranean Sea current around Corsica Island.

where $\rho_{\text {sky }}$ is the air-water interface reflection coefficient for radiance. In the case of a flat sea surface $\rho_{\text {sky }}$ is equal to the Fresnel reflection coefficient and is assumed to be 0.02 for clear skies for satellite 'matchups' (Ruddick et al., 2006). Residual skylight was removed using baseline correction following Mobley (1999). The normalized water leaving radiance $\left(n L_{w}\right)$ was calculated from:

$n L_{w}(\lambda)=\frac{\rho_{w}(\lambda)}{\pi} \times f_{0}(\lambda)\left(\right.$ in $\left.\mathrm{mW} \mathrm{cm}^{-2} \mu \mathrm{m}^{-1} \mathrm{sr}^{-1}\right)$

where $f_{0}(\lambda)$ is the mean solar flux above the earth's atmosphere. $R_{r s}(\lambda)$ $\left(\mathrm{sr}^{-1}\right)$ was then calculated from:

$R_{r s}(\lambda)=\frac{L_{w}(\lambda)}{E_{S}\left(\lambda, 0^{+}\right)}$

where $E_{S}\left(\lambda, 0^{+}\right)$is the above surface downwelling spectral irradiance (W $\mathrm{m}^{-2} \mathrm{~nm}^{-1}$ ) and $L_{W}(\lambda)$ is the water leaving radiance $\left(\mathrm{W} \mathrm{m} \mathrm{m}^{-2} \mathrm{~nm}^{-1} \mathrm{sr}^{-1}\right.$ ). NASA ocean optics protocols were used to compute $L_{w}(\lambda), n L_{w}(\lambda)$ and $R_{r s}(\lambda)$ (Mueller, 2000). Surface downwelling irradiance $\left(E_{s}\left(\lambda, 0^{+}\right)\right)$was calculated from:

$E_{S}\left(\lambda, 0^{+}\right)=(1+\alpha) E_{d}\left(\lambda, 0^{-}\right)$

where $\alpha$ is the Fresnel reflection albedo from air + sky ( 0.043), and $E_{d}\left(\lambda, 0^{-}\right)$is extrapolated from the $E_{d}(\lambda, z)$ profile.
CIMA collected in situ radiometric measurements at three sampling stations off South West Portugal, following MERIS protocols (Barker, 2011; Doerffer, 2002). Measurements of $\rho_{w}$ were acquired with a Satlantic tethered attenuation coefficient chain sensor (TACCS), which consists of a floating buoy encasing a hyperspectral surface irradiance sensor $\left(E_{\mathrm{s}}(\lambda)\right)$ and a subsurface radiance sensor $\left(L_{\mathrm{u}}(\lambda)\right)$ located $0.62 \mathrm{~m}$ below the surface and a tethered attenuation chain supporting four subsurface irradiance sensors $E_{\mathrm{d}}(\mathrm{z})$ at $2,4,8$, and $16 \mathrm{~m}$. Further details of the processing of $E_{\mathrm{s}}, L_{\mathrm{u}}$ and $E_{\mathrm{d}}$ are given in (Cristina et al., 2014; Cristina et al., 2009). The $\rho_{w}$ acquired by the TACCS was calculated from:

$\rho_{w}(\lambda)=\pi \frac{L_{w}(\lambda)}{E_{s}(\lambda)}$

where $\rho_{w}$ is equivalent to $R_{r s}$ (Eq. (3)) when scaling by a factor of $\pi$ (i.e. $\left.R_{r s}=\rho_{w} / \pi\right)$.

Measurements taken by LOV were obtained from the radiometric data buoy BOUSSOLE using the methods described in Antoine et al. (2008).

\subsection{Measurement of Chlorophyll-a}

On all cruises, surface water samples were collected using $10 \mathrm{~L}$ Niskin bottles and between 0.25 . 
between 0.25 and $2 \mathrm{~L}$ of seawater were filtered onto $0.7 \mu \mathrm{m} \mathrm{GF} / \mathrm{F}$ filters. PML, MARE and CIMA used High Performance Liquid Chromatography (HPLC) to determine Chl $a$. PML extracted phytoplankton pigments into $2 \mathrm{~mL} 100 \%$ acetone containing an internal standard (apocarotenoate; Sigma) using an ultrasonic probe (35 s, 50 W). Extracts were centrifuged to remove filter and cell debris ( $3 \mathrm{~min}$ at $20 \mathrm{xg}$ ) and analysed by HPLC using a reversed phase C8 column and gradient elution (Barlow et al., 1997) on an Agilent 1100 Series system with chilled autosampler $\left(4^{\circ} \mathrm{C}\right)$ and photodiode array detection (Agilent Technologies). CIMA extracted the pigments in 90\% acetone for 4-6 h in a refrigerator $\left(-4{ }^{\circ} \mathrm{C}\right)$ and using an ultrasonic probe for $20 \mathrm{~s}$ before and after refrigeration. Extracts were centrifuged and then analysed either on a Waters 600E HPLC system with diode array detector and a C8 Thermo Hypersil-Keystone (ODS-2) column or on an Agilent HPLC with diode array using a C8 Alltech Altima column following Goela et al. (2014). MARE extracted pigments with $2-5 \mathrm{~mL}$ of $95 \%$ cold-buffered methanol ( $2 \%$ ammonium acetate) for $30 \mathrm{~min}$ to $1 \mathrm{~h}$ at $-20^{\circ} \mathrm{C}$, in the dark. Pigment extracts were analysed using a Shimadzu HPLC comprising a solvent delivery module (LC-10ADVP) with system controller (SCL-10AVP), a photodiode array (SPD-M10ADVP), and a fluorescence detector (RF-10AXL). Chromatographic separation was carried out with a C8 column, following Zapata et al. (2000). PML, CIMA and MARE calibrated the HPLC system using a suite of standards (DHI) Water and Environment, Denmark and pigments in samples identified from retention time and spectral match using photodiode array spectroscopy (Jeffrey et al., 1997). Chl $a$ concentration was calculated using response factors generated from calibration using a Chl $a$ standard (DHI Water and Environment, Denmark). Samples taken by IFREMER along the North France coast were measured by spectrophotometry using the methods outlined in Lorenzen (1967).

\subsection{Measurement of suspended particulate material (SPM)}

All laboratories filtered between 0.5 and $3 \mathrm{~L}$ of seawater onto $47 \mathrm{~mm}$, $0.7 \mu \mathrm{m} \mathrm{GF} / \mathrm{F}$ filters in triplicate. The filters were ashed at $450{ }^{\circ} \mathrm{C}$, washed for 5 mins in $0.5 \mathrm{~L}$ of MilliQ and then dried in a hot air oven at $75^{\circ} \mathrm{C}$ for one hour, pre-weighed and stored in desiccators (Van der Linde, 1998). Seawater samples were filtered in triplicate onto the pre-prepared filters which were then washed (including the rim) three times with 0.05 L MilliQ to remove residual salt. Blank filters were also washed with MilliQ to quantify any potential error due to incomplete drying. The filters were then dried at $75^{\circ} \mathrm{C}$ for $24 \mathrm{~h}$ and weighed on microbalances (detection limit $10 \mu \mathrm{g}$ ). SPM concentrations were determined from the difference between blank and sample filters and the volume of seawater filtered.

\subsection{Measurement of CDOM absorption coefficients $\left(a_{\mathrm{CDOM}}(\lambda)\right)$}

All laboratories filtered replicate seawater samples through $0.2 \mu \mathrm{m}$ Whatman Nuclepore membrane filters into acid cleaned glassware. The first two $0.25 \mathrm{~L}$ of the filtered seawater were discarded. $a_{\text {СDOM }}(\lambda)$ was determined using the third sample in a $10 \mathrm{~cm}$ quartz cuvette from 350 to $750 \mathrm{~nm}$ relative to a bi-distilled MilliQ reference blank and was calculated from the optical density of the sample and the cuvette path length following the protocols given in Tilstone et al. (2004).

\subsection{Satellite data and algorithms}

MERIS full resolution (300 m) COASTCOLOUR v2013 and reduced resolution $(1 \mathrm{~km})$ MEGS8.0 data were downloaded from Brockman Consult and extracted using Beam v4.8. Both MEGS8.0 and COASTCOLOUR L2 $R_{r s}$ were used to process five Chl $a$ algorithms. MEGS8.0 processor has a two-step approach to atmospheric correction; if there is any signal in the NIR due to backscattering by sediment or coccolithophores, the Bright Pixel AC (Moore and Lavender, 2010) is triggered (Lerebourg et al., 2011). If this is not triggered, the Clear Water Atmospheric Correction model is implemented (Antoine and Morel, 1997). The COASTCOLOUR AC is an NN based inversion technique that implements a forward model configured with a set of regional, coastal aerosol optical properties (Brockmann, 2011) collected from the global AERONET network (Zibordi et al., 2009b).

The following MERIS quality flags were used to eliminate erroneous data generated from the processors: cloud flag over ocean (CLOUD), land (LAND), no glint correction applied - accuracy uncertain (HIGH_GLINT), reflectance corrected for medium glint - accuracy maybe degraded (MEDIUM_GLINT), highly absorbing aerosols (AODB), low sun angle (LOW_SUN), low confidence flag for water leaving or surface reflectance (PCD1_13) and reflectance out of range (PCD_15). The MERIS L2 products were extracted from a $3 \times 3$ pixel box, within $\pm 0.5 \mathrm{~h}$ of MERIS overpasses. The functional form of each of the Chl $a$ algorithms tested is given in Table 1 and described in brief below.

The first Chl $a$ algorithm tested was the standard Case 2 MERIS Chl $a$ product (AP2) (Doerffer and Schiller, 2007; Schiller and Doerffer, 2005), which uses an NN to derive the $a_{p h}$ and the particulate scattering coefficient $\left(b_{p}\right)$, and through empirical bio-optical relationships, Chl $a$, SPM and $a_{d g}$ are computed. An inverse model solves the IOPs from $R_{r s}(\lambda)$ using a Look Up Table. The total absorption coefficient $\left(a_{t o t}\right)$ is then apportioned into $a_{p h}$ and $a_{d g}$ and empirical solutions are used to convert $a_{p h}$ to Chl $a$ and the $b_{b p}$ to SPM. The AP2 algorithm was calibrated using a global dataset, which included a large IOP data set from North Sea coastal waters of the German Bight. AP2 solves Chl $a$ from $a_{p h}$ as follows; Chl $a=21.0 * a_{p h}(442)^{1.04}$ (Table 1).

The second algorithm tested is the default MERIS Case $1 \mathrm{Chl} a$ algorithm (AP1; also known as OC4Me). OC4Me is the MERIS algal pigment 1 fourth-order polynomial algorithm, that was parameterised using a theoretical model (Morel and Maritorena, 2001), and tuned using Kd and Chl $a$ data given in Morel and Antoine (2011). It uses the maximum Remote Sensing Reflectance ratio from: $R_{r s} 442 / 560, R_{r s} 490 / 560$ or $510 / 560$. The switch between $R_{r s} 442 / 560$ and $R_{r s} 490 / 560$ theoretically occurs at a Chl $a$ concentration of $0.534 \mathrm{mg} \mathrm{m}^{-3}$ and between $R_{r s}$ $490 / 560$ and $R_{r s} 510 / 560$ at $2.23 \mathrm{mg} \mathrm{m}^{-3}$. Chl $a$ was estimated using the equation given in Table 1 , where $\rho$ is the maximum $R_{r s}(\lambda) / 560$ ratio.

Table 1

Functional form of MERIS Chl $a$ algorithms.

\begin{tabular}{|c|c|c|}
\hline Algorithm & Reference & Functional form \\
\hline AP2 & Doerffer and Schiller (2007) & Chl $a=21.0 * a_{p h}(442)^{1.04}$ \\
\hline \multirow[t]{2}{*}{ OC4Me } & Morel and Antoine (2011) & Chl $a=10^{\left(a+b R+c R^{2}+d R 5+e R 4\right)}$ \\
\hline & & where $R=$ max ratio of $\log _{10}\left\{\left[\left(\frac{R_{r 5} 443}{R_{r 5} 560}\right),\left(\frac{R_{r 5} 490}{R_{r 5} 560}\right)\left(\frac{R_{r 5} 510}{R_{r 5} 560}\right)\right]\right\}$ \\
\hline \multirow[t]{3}{*}{ OC3Me } & O'Reilly et al. (2000) & $\begin{array}{l}\mathrm{a}=0.4502748 ; \mathrm{b}=-3.259491 ; \mathrm{c}=3.52271 ; \mathrm{d}=-3.359422 ; \mathrm{e}=0.949586 \\
\text { Chl } a=10^{\left(a+b R+c R^{2}+d R 5+e R 4\right)}\end{array}$ \\
\hline & & where $R=$ max ratio of $\log _{10}\left\{\left[\left(\frac{R_{r} 442}{R_{r} 560}\right),\left(\frac{R_{r} 490}{R_{r 5} 560}\right)\right]\right\}$ \\
\hline & & $\mathrm{a}=0.40657 ; \mathrm{b}=-3.6303 ; \mathrm{c}=5.44357 ; \mathrm{d}=0.0015 ; \mathrm{e}=-1.228$ \\
\hline GSM & Maritorena et al. (2002) & $\mathrm{L}_{\mathrm{wN}}(\lambda)=\frac{t F_{0}(\lambda)}{n_{w}^{2}} \sum_{i=1}^{2} g_{i}\left\{\frac{\left[b_{b b}(\lambda)+b_{b p}(442)(\lambda / 442)^{-1.0337}\right]}{\left[b_{b w}(\lambda)+b_{b p}(442)(\lambda / 442)^{-1.0337}\right]+\left[a_{w}(\lambda)+C h l a \times a_{p h}^{*}(\lambda)+a_{\text {CDDM }}(442) \times e^{-0.0206(\lambda-442)}\right]}\right\}^{i}$ \\
\hline OC5Me & Gohin et al. (2002) & Chl $a=\mathrm{F}$ (triplet); where triplet $=\{$ max of the reflectance ratios as in OC4Me, $\mathrm{nLw}(412), \mathrm{nLw}(560)]$ \\
\hline
\end{tabular}



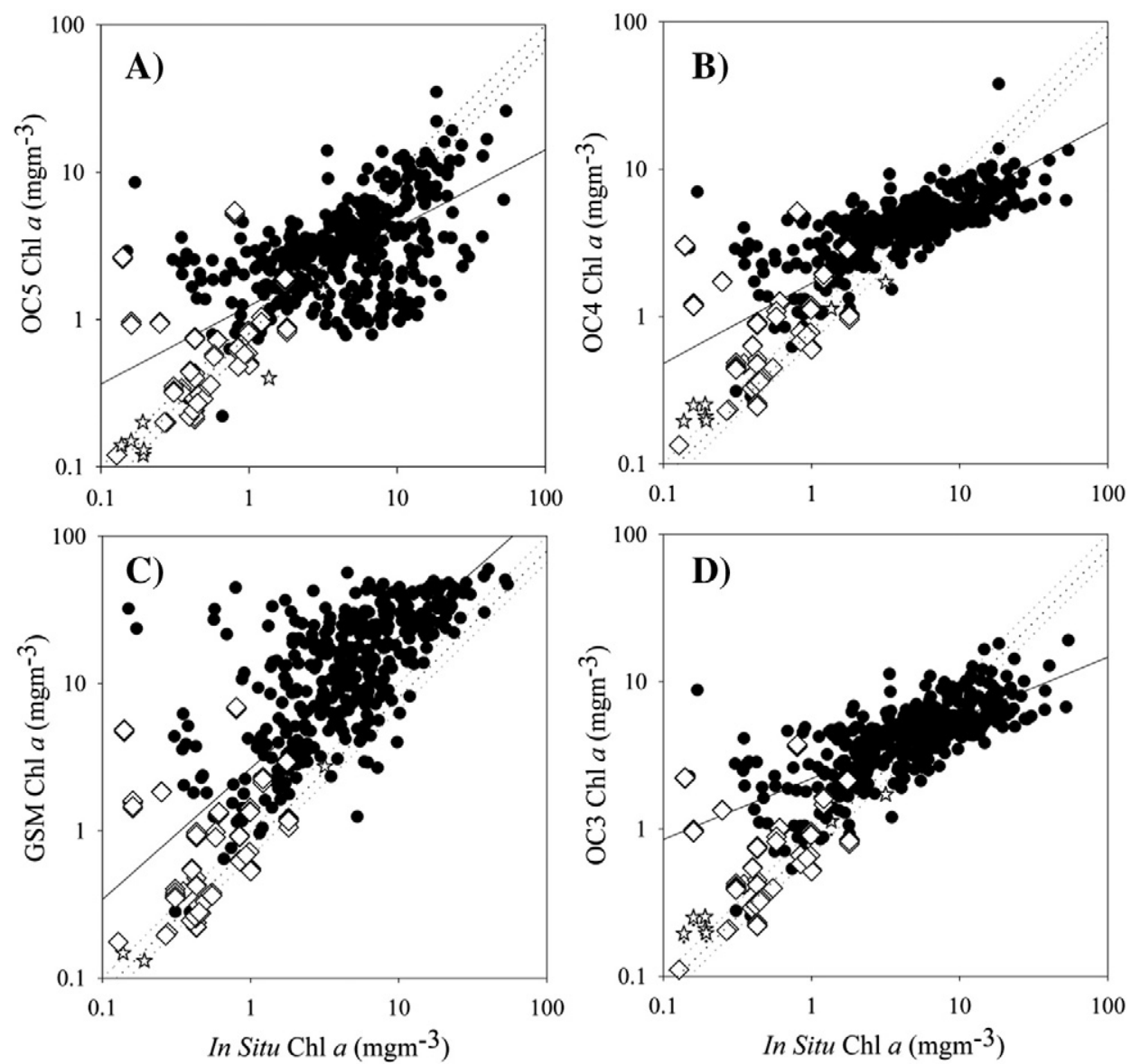

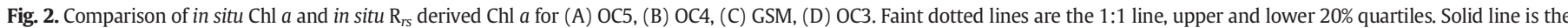
regression line. Filled circles are North Sea data, open diamonds are Portuguese coast, open stars are Mediterranean coast.

OC3Me is an empirical fourth-order band ratio algorithm that uses one of two $R_{r s}(\lambda) / R_{r s}(560)$ ratios; either $R_{r s}(442) / R_{r s}(560)$ or $R_{r s}(490) /$ $R_{r s}(560)$, depending on the reflectance characteristics of the water type (O'Reilly et al., 2000). It is the default Case 1 water algorithm for MODIS-Aqua and has been adapted for MERIS using the maximum
Remote Sensing Reflectance ratio from: $R_{r s} 442 / 560$ or $R_{r s} 490 / 560$ and the coefficients for OC3Me adapted for MERIS given in Table 1.

OC5Me is a modified version of OC4Me, which includes an empirical parameterisation of 412 and $560 \mathrm{~nm}$ channels for MERIS related to the absorption of CDOM and scattering of SPM (Novoa et al., 2012;

Table 2

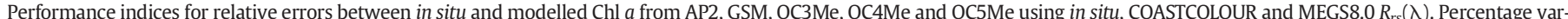

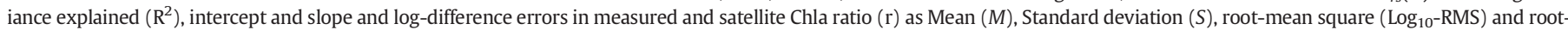

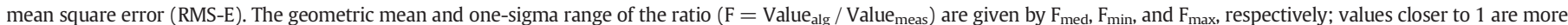
accurate. RPD is the relative percentage difference. The algorithm with the highest Chl $a$ accuracy is highlighted in bold.

\begin{tabular}{|c|c|c|c|c|c|c|c|c|c|c|c|c|}
\hline$R_{r s}(\lambda)$ & $\mathrm{R}^{2}$ & Slope & Intercept & $\mathrm{r}$ & RPD & $\log _{10}$-RMS & $\mathrm{M}$ & $S$ & $\mathrm{~F}_{\text {med }}$ & $\mathrm{F}_{\max }$ & $\mathrm{F}_{\min }$ & RMS-E \\
\hline \multicolumn{13}{|c|}{ In situ $\mathrm{N}=482$. (North Sea, $\mathrm{N}=384 ;$ Portugal, $\mathrm{N}=87 ;$ Med, $\mathrm{N}=12$ ). } \\
\hline OC3Me & 0.41 & 0.23 & 3.07 & 0.92 & -9 & 0.23 & -0.03 & 0.23 & 0.93 & 1.57 & 0.55 & 4.97 \\
\hline OC4Me & 0.50 & 0.24 & 2.54 & 0.76 & 24 & 0.24 & -0.02 & 0.24 & 0.95 & 1.66 & 0.55 & 5.77 \\
\hline GSM & 0.47 & 1.34 & 6.41 & 1.13 & -61 & 0.43 & 0.29 & 0.31 & 1.96 & 4.01 & 0.96 & 27.20 \\
\hline OC5Me & 0.38 & 0.32 & 1.54 & 0.80 & 104 & 0.33 & -0.11 & 0.28 & 0.78 & 1.49 & 0.41 & 5.90 \\
\hline \multicolumn{13}{|c|}{ COASTCOLOUR N = 113 (North Sea, $N=18 ;$ WEC, $N=16 ;$ Portugal, $N=66 ;$ Med, $N=13$ ). } \\
\hline AP2 & 0.61 & 0.71 & 0.61 & 1.42 & 83 & 0.44 & 0.03 & 0.43 & 1.07 & 2.92 & 0.39 & 2.46 \\
\hline OC3Me & 0.65 & 0.72 & 0.26 & 2.05 & 64 & 0.42 & 0.05 & 0.42 & 1.12 & 2.92 & 0.43 & 2.10 \\
\hline OC4Me & 0.67 & 0.76 & 0.46 & 0.68 & 20 & 0.43 & -0.09 & 0.42 & 0.81 & 2.14 & 0.31 & 2.04 \\
\hline $\mathrm{GSM}^{\mathrm{a}}$ & 0.61 & 0.99 & 0.10 & 2.42 & 105 & 0.40 & 0.05 & 0.54 & 1.13 & 3.89 & 0.33 & 2.01 \\
\hline OC5Me & 0.75 & 0.65 & 0.26 & 1.58 & 63 & 0.39 & 0.06 & 0.39 & 1.14 & 2.79 & 0.44 & 2.14 \\
\hline \multicolumn{13}{|c|}{ MEGS8.0 $\mathrm{N}=88$ (North Sea, $\mathrm{N}=18$; WEC, $\mathrm{N}=9$; Portugal, $\mathrm{N}=45$; Med, $\mathrm{N}=16$ ). } \\
\hline AP2 & 0.31 & 0.42 & 0.72 & 1.42 & 103 & 0.47 & 0.09 & 0.46 & 1.24 & 3.56 & 0.43 & 2.41 \\
\hline OC3Me & 0.51 & 0.64 & 0.48 & 1.32 & 42 & 0.32 & 0.04 & 0.32 & 1.11 & 2.29 & 0.54 & 1.98 \\
\hline OC4Me & 0.55 & 0.83 & 0.63 & 0.62 & 25 & 0.32 & -0.09 & 0.31 & 0.81 & 1.65 & 0.40 & 2.14 \\
\hline $\mathrm{GSM}^{\mathrm{b}}$ & 0.58 & 0.60 & 0.40 & 1.51 & 84 & 0.36 & 0.11 & 0.34 & 1.30 & 2.85 & 0.59 & 2.54 \\
\hline OC5Me & 0.87 & 0.62 & 0.18 & 1.05 & 46 & 0.27 & 0.10 & 0.25 & 1.25 & 2.21 & 0.71 & 1.61 \\
\hline
\end{tabular}

${ }^{a}$ For GSM Chl $a$ calculated using COASTCOLOUR $R_{r s}, \mathrm{~N}=89$ match-ups were available (North Sea, $\mathrm{N}=11 ; \mathrm{WEC}, \mathrm{N}=0$; Portugal, $\mathrm{N}=65 ; \mathrm{Med}, \mathrm{N}=13$ ).

b For GSM Chl $a$ calculated using MEGS8.0 $R_{r s}, \mathrm{~N}=81$ match-ups were available (North Sea, $\mathrm{N}=18$; WEC, $\mathrm{N}=2$; Portugal, $\mathrm{N}=45 ; \mathrm{med}, \mathrm{N}=16$ ). 
Saulquin et al., 2011). Chl $a$ concentration is determined from the triplet values of OC4Me maximum band ratio, $n L_{w}(412)$ and $n L_{w}(560)$, from a Look Up Table (LUT), based on the relationships between measured Chl $a$ and satellite $R_{r s}(\lambda)$ from observations in the English Channel and Bay of Biscay (Gohin et al., 2002). The method has also been extended to the Mediterranean Sea and applied to MODIS-Aqua and MERIS (Gohin, 2011). OC5 satellite images using both MODIS-Aqua and MERIS are available from https://www.neodaas.ac.uk/multiview/pa/

The GSM is an optimized semi-analytical algorithm that simultaneously retrieves Chl $a, a_{d g}$ and $b_{b p}$ at $442 \mathrm{~nm}$, from spectral measurements of $n L_{w}(\lambda)$. The parameters for the model were obtained through simulated annealing which is a global optimization technique (Maritorena et al., 2002). The model was originally parameterised for SeaWiFS and in this paper has been adapted for MERIS using the amoeba implementation from SeaDAS with an update of the absorption spectrum values for pure water (Pope and Fry, 1997) to (Kou et al., 1993) which extend the spectrum beyond $700 \mathrm{~nm}$ to 709,753 \& $778 \mathrm{~nm}$ for MERIS.

The concentration of non-algal SPM (the inorganic component of SPM that is not related to phytoplankton) was derived using the method developed in Gohin et al. (2005). Once Chl $a$ has been determined using OC5Me, non-algal SPM is estimated from $n L_{w}(560)$ or $n L_{w}(670)$
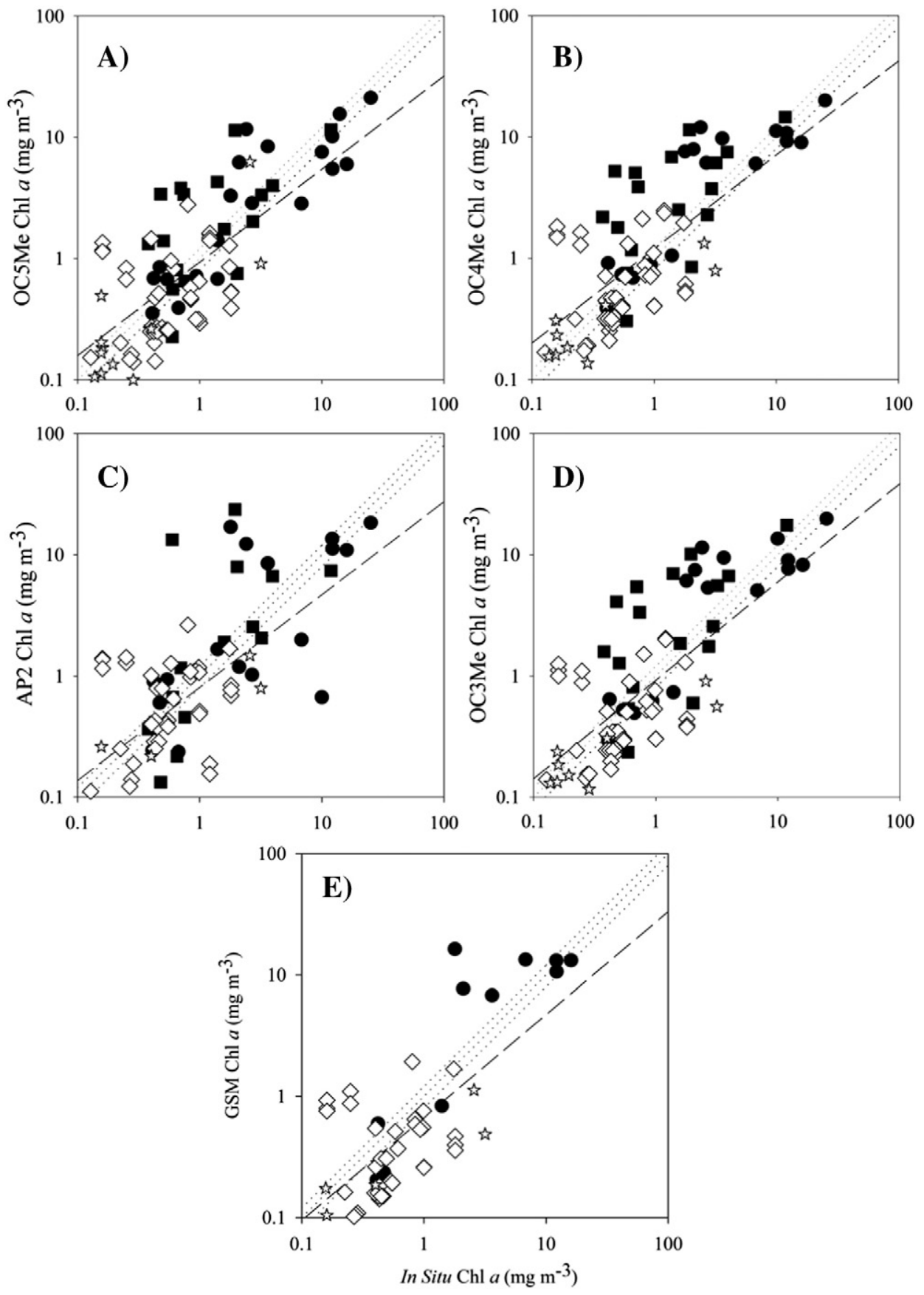

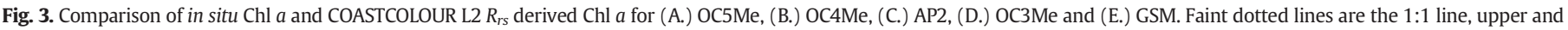

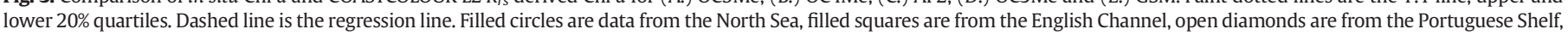
open stars are the Mediterranean Sea. 
by inverting the semi-analytic model. $n L_{w}(560)$ is used in clear or moderately turbid waters (where non-algal SPM $<4 \mathrm{~g} \mathrm{~m}^{-3}$ ) and $n L_{w}(670)$ for highly turbid waters (Gohin, 2011).

\subsection{Algorithm performance}

The performance of the Chl $a$ algorithms was assessed in four ways: (1.) using 482 coincident in situ measurements of $R_{r s}(\lambda)$ and Chl $a$; the in situ $R_{r s}(\lambda)$ were used to run the algorithms and the resulting Chl $a$ values were compared against the in situ Chl a (Fig. 2, Table 2). (2.) A data base of 594 in situ HPLC and fluorometric Chl $a$ (which includes the 482 coincident in situ $R_{r s}(\lambda)$ and Chl $a$, plus additional Chl $a$ measurements) comprising data from the Celtic Sea (PML), Eastern English Channel (IFREMER), Iberian Peninsula (CIMA \& MARE), North Sea (RBINS \& PML), Mediterranean Sea (LOV) and Western English Channel (PML) (Fig. 1B), were compared against Chl $a$ match-ups from MERIS overpasses using COASTCOLOUR (Fig. 3, Table 2) and MEGS 8.0 (Fig. 4, Table 2) data. MERIS match-ups \pm 0.5 h between in situ sampling and MERIS data from a $3 \times 3$ pixel array around the sampling station were extracted to compare against in situ $\mathrm{Chl} a$ following the procedures outlined in (Bailey and Werdell, 2006). The Chl $a$ algorithms yielded a varying number of match-ups depending on the input $R_{r s}(\lambda)$ used and the associated quality flags raised. To facilitate statistical comparison, common returns for OC5Me, OC4Me, OC3Me \& AP2 were used. (3.)
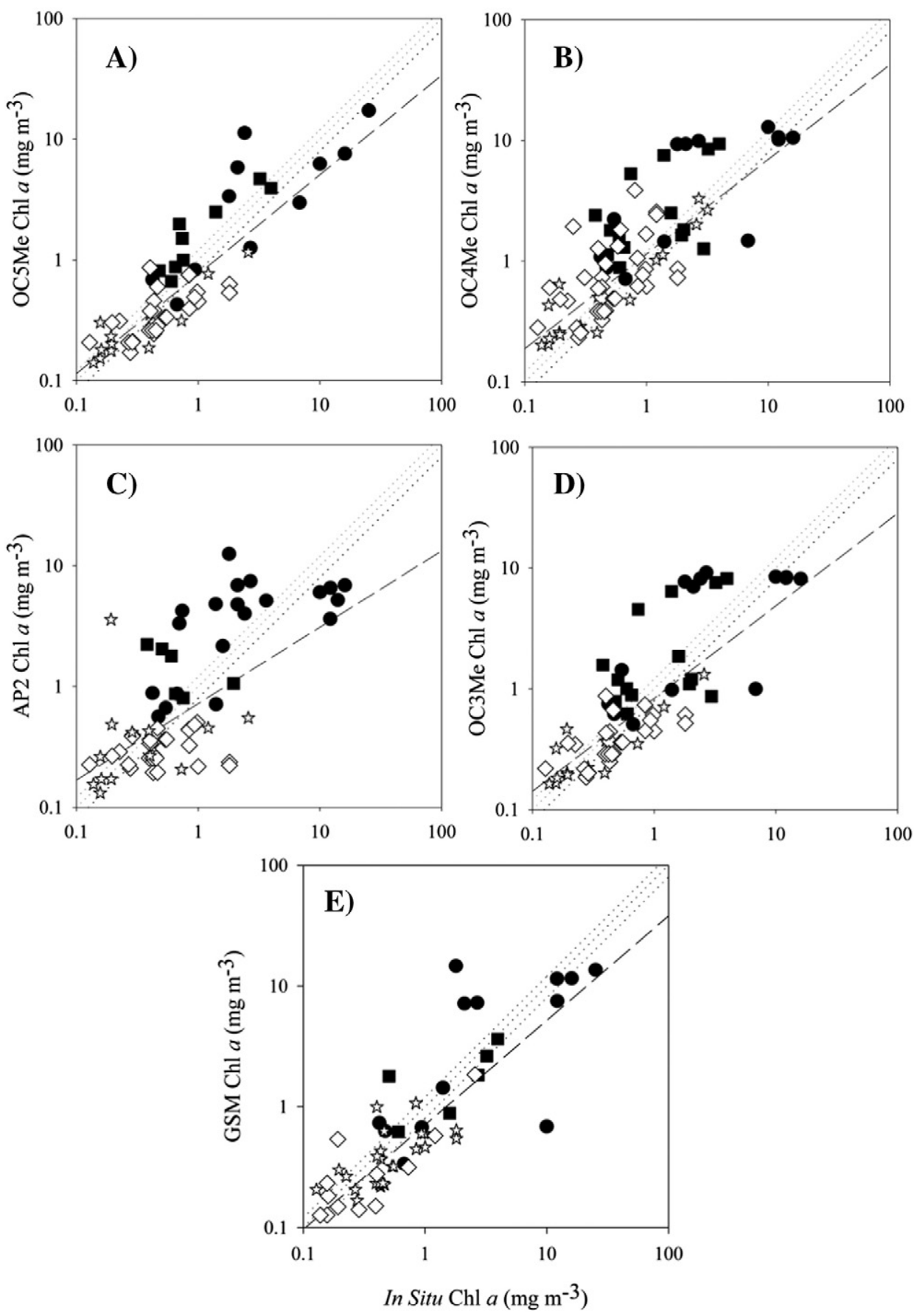

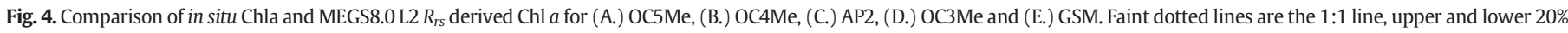

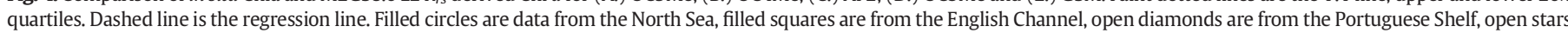
are the Mediterranean Sea. 
MERIS MEGS 8.0 Chl $a$ values from AP2, OC4Me and OC5Me were compared along transects in the North Sea from the Thames Estuary in the UK $\left(51.47^{\circ} \mathrm{N}, 0.59^{\circ} \mathrm{E}\right)$ to the Schelde Estuary in the Netherlands $\left(51.49^{\circ} \mathrm{N}, 3.31^{\circ} \mathrm{E}\right)$ and from the Schelde Estuary $\left(51.49^{\circ} \mathrm{N}, 4.13^{\circ} \mathrm{E}\right)$ to
The Wash in the UK $\left(52.67^{\circ} \mathrm{N}, 2.01^{\circ} \mathrm{E}\right)$. Chl $a$ values were extracted at every $10 \mathrm{~km}$ along each transect from daily images between March and September from 2003 to 2007 (Fig. 5). (4.) Monthly composite images from AP2, OC4Me, GSM and OC5Me using MERIS MEGS 8.0 Chla
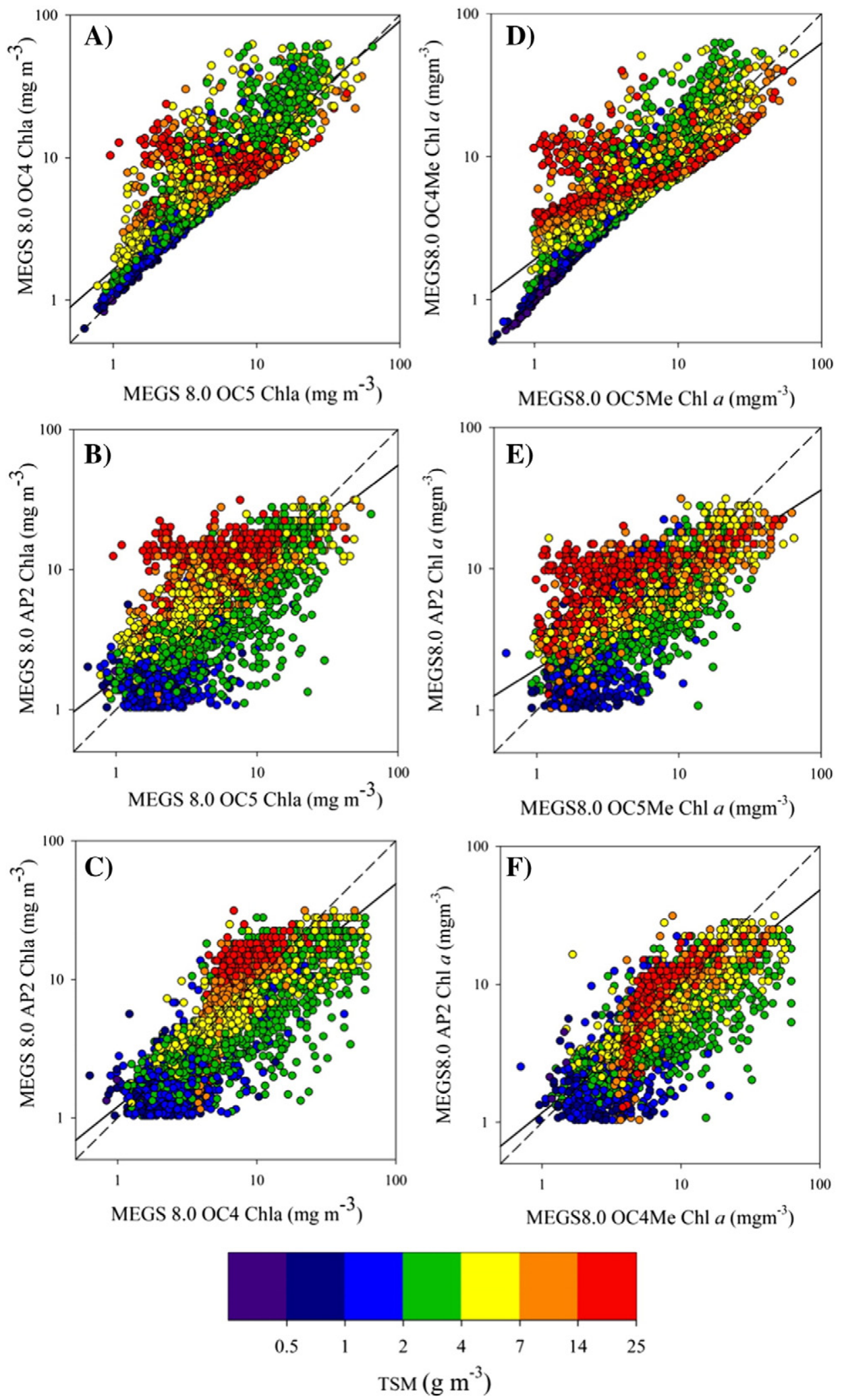

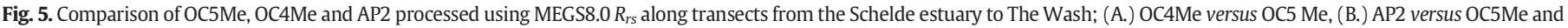

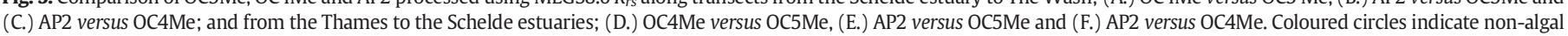
SPM concentration $\left(\mathrm{g} \mathrm{m}^{-3}\right)$ estimated using the Gohin (2011) algorithm. 
were compared for the months of April 2010 and July 2011 (Figs. 6, 7). Additional data were extracted from a transect from the UK coast in the Western English Channel $\left(50.25^{\circ} \mathrm{N}, 4.21^{\circ} \mathrm{W}\right)$ to the River Seine on the French coast $\left(49.42^{\circ} \mathrm{N}, 0.14^{\circ} \mathrm{E}\right)$ at every $10 \mathrm{~km}$ to evaluate spatial differences in algorithm performance for these images (Fig. 8).

To assess algorithm performance, the following statistical metrics were used: The mean (M), standard deviation (S), and $\log _{10}$-rootmean square ( $\log _{10}$ RMS) of the difference error $(r)$ between measured and MERIS Chl $a$ at each station following the methods described in Campbell et al. (2002). The geometric mean and one-sigma range of the inverse transformed ratio between satellite and measured values are given by $\mathrm{M}\left(\mathrm{F}_{\mathrm{med}}\right), \mathrm{M}-\mathrm{S}\left(\mathrm{F}_{\min }\right), \mathrm{M}+\mathrm{S}\left(\mathrm{F}_{\max }\right)$ and were used as algorithm performance indices. The relative percentage difference (RPD) was calculated following Antoine et al. (2008). The uncertainty in MEGS8.0 and COASTCOLOUR $R_{r s}(\lambda)$ were assessed against in situ $R_{r s}(\lambda)$ at match-up stations. The relative difference between in situ and satellite $R_{r s}(\lambda)$ was calculated following Hu et al. (2013) and expressed as percentage uncertainty over the range in in situ Chl $a$ and SPM (Fig. 11).

\section{Results}

3.1. Accuracy assessment of ocean colour algorithms for MERIS in North West European waters using in situ $R_{r s}(\lambda)$

Firstly we assessed the accuracy of the algorithms using in situ $R_{r s}$ to calculate Chl $a$ (Fig. 2, Table 2) measured at the stations given in Fig. 1A. The majority of in situ $R_{r s}$ used to compute algorithm Chl $a$ values were from the North Sea, which comprised $80 \%$ of the dataset. In situ $R_{r S}$ from the Portuguese coast and Mediterranean Sea constituted 20\% of the data set. The log-RMS, RMS-E bias and random error were smallest for
OC4Me and OC3Me. The percentage variance explained $\left(R^{2}\right)$ was greatest for OC4Me and OC3Me had the lowest RPD, which was within 24 and $9 \%$ of in situ Chl $a$, respectively (Fig. 2B, D, Table 2). The linear regression slope and $\mathrm{F}_{\min }$ for GSM were closest to 1, indicating that the GSM is more accurate at the lower range of Chl $a$ values when using in situ $R_{r s}$. The GSM however, had the highest log-RMS, RMS-E, $\mathrm{F}_{\max }, \mathrm{F}_{\text {med }}$ and intercept (Fig. 2C, Table 2), which suggests that it may not be suitable for these coastal waters. By comparison, OC5 had the lowest intercept and $\mathrm{F}_{\max }$ closest to 1 , indicating that it is more accurate at the higher range Chl $a$ values when using these in situ $R_{r s}$ data (Fig. 2A, Table 2). The processing of AP2 using in situ $R_{r s}$ was not possible as the atmospheric correction is embedded within the standard AP2 processor such that any other input source of $R_{r s}$ other than MERIS $R_{r s}$, is not feasible.

\subsection{Accuracy assessment of MERIS MEGS8.0 and COASTCOLOUR Chl a products in North West European waters}

Using COASTCOLOUR L2 $R_{r s}$ to test algorithm accuracy (Fig. 3, Table 2), OC4Me had the lowest RPD and $r$ and $F_{\max }$ closest to 1. The GSM had the lowest intercept and RMS-E and slope closest to 1, though fewer match-ups were available using the GSM, since the algorithm did not converge at some stations in the North Sea and at all of the English Channel stations (Table 2). OC5Me had the lowest $\log _{10}$-RMS, M and S and $\mathrm{R}^{2}$ and $\mathrm{F}_{\min }$ closest to 1 . OC5Me with COASTCOLOUR L2 $R_{r s}$ had a similarly low intercept, random error and RMS-E and $F_{\text {med }}$ compared to the GSM and AP2. Of the algorithms tested using COASTCOLOUR L2 $R_{r s}$, AP2 was the least accurate (Table 2, Fig. 3).

Similarly using MEGS8.0 L2 $R_{r s}$, OC4Me had the lowest RPD and OC3Me had the lowest random error (Table 2, Fig. 4B, D). OC5Me had the lowest $\log _{10}$-RMS, RMS-E, intercept and bias, the highest $\mathrm{R}^{2}$ and
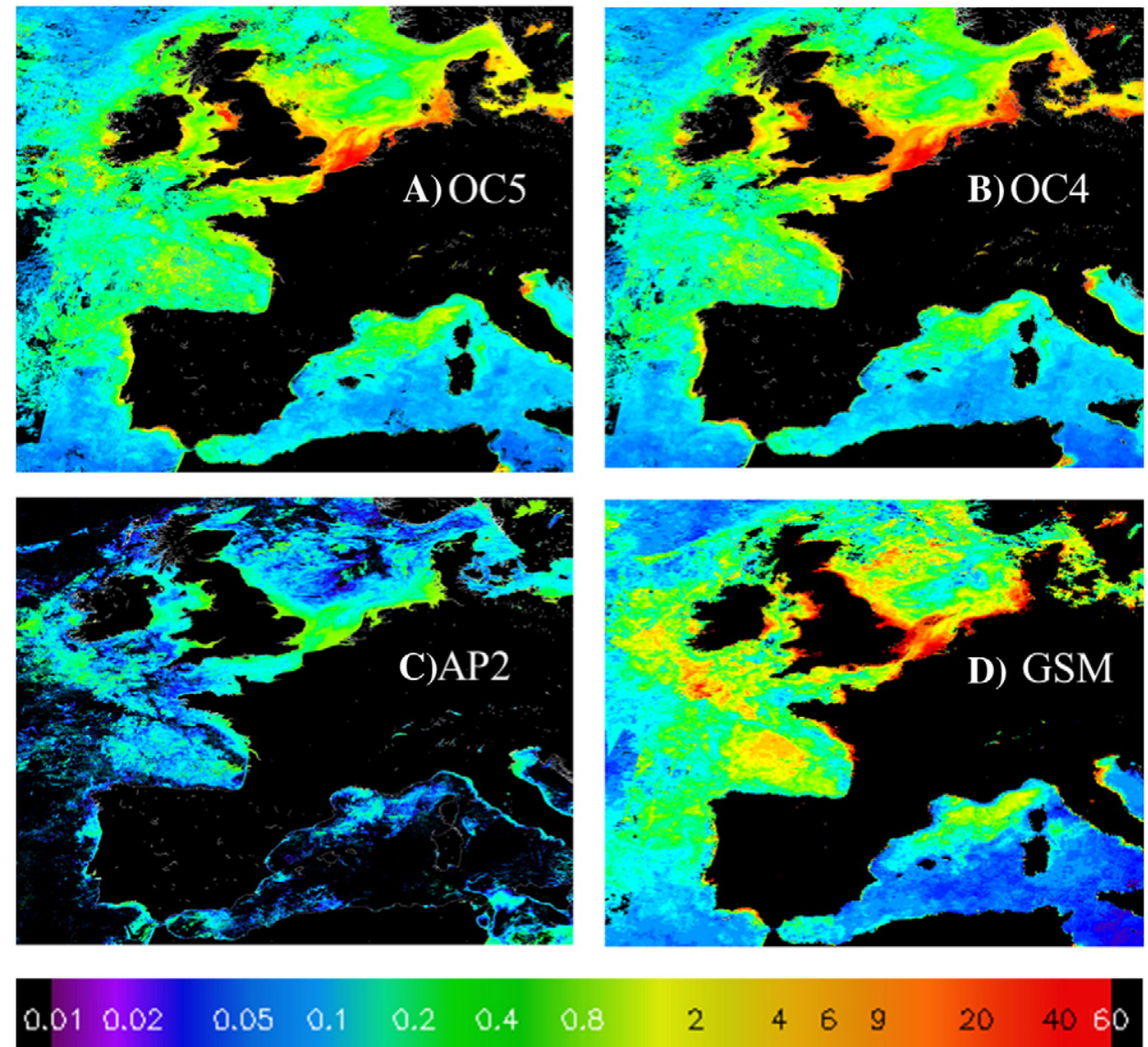

Fig. 6. Comparison of MERIS MEGS8.0 Chl a monthly composites for April 2010 using (A.) OC5Me, (B.) OC4Me, (C.) AP2, (D.) GSM. 
the slope, $r$, and $\mathrm{F}_{\min }$ closest to 1 and was the most accurate algorithm in 7 out of the 12 statistical tests performed (Table 2, Fig. 4A). GSM also had $\mathrm{F}_{\text {min }}$ close to 1 whereas $\mathrm{F}_{\max }$ was high, indicating that it is more accurate at lower rather than at higher Chl $a$ concentrations (Table 2, Fig. $4 \mathrm{E})$. For GSM with MEGS8.0 L2 $R_{r s}$, there were only four data points that exhibited high scatter from the 1:1 line, and in the absence of these, this algorithm would have been accurate for these coastal waters. Where the other algorithms returned data, the GSM did not converge at some stations in the English Channel however, questioning its suitability for providing contiguous satellite imagery. AP2 was the least accurate across all statistical tests (Table 2, Fig. 4C). Of the MEGS8.0 and COASTCOLOUR match-ups, 17\% were from the North Sea, 13\% from the English Channel, $55 \%$ were from the Portuguese coast and 15\% from the Mediterranean. Comparing MEGS8.0 and COASTCOLOUR OC5Me Chl $a$ against in situ Chl $a$ and using the same number of match-ups (figure not shown), MEGS8.0 OC5Me had a lower bias and log-RMS and a higher percentage variance explained compared to COASTCOLOUR OC5Me, indicating that OC5Me Chl $a$ is slightly more accurate using MEGS8.0 compared to COASTCOLOUR $R_{r s}$ (Table 2, Figs. 3A, 4A).

\subsection{Spatial comparison between MERIS ocean colour algorithms in the North Sea}

A comparison of Chl $a$ from MERIS algorithms along two transects from the Schelde Estuary and to the Wash on the SE UK coast and from the Schelde to the River Thames estuary across the Southern Bight of the North Sea using data from January 2003 to December 2007 (Figs. 1C, 5). For these two transects over the $6 \mathrm{yr}$ period, there were 68,332 data points; for coincident OC5Me, OC4Me AP2 and nonalgal SPM data there were 7776 data. Comparison between OC4Me and OC5Me explained $58 \%$ of the variance in the data with a slope close to 1 , but a high intercept (Table 3 ). At Chl $a>1 \mathrm{mg} \mathrm{m}^{-3}$ OC5Me, OC4Me tended to over-estimate Chl $a$ which were $\sim 10 \mathrm{mg} \mathrm{m}^{-3}$ (Fig. $5 \mathrm{~A}, \mathrm{D})$. At OC5Me Chl $a$ between 1 and $10 \mathrm{mg} \mathrm{m}^{-3}$, the over-estimate in OC4Me Chl $a$ was related to high non-algal SPM $>14 \mathrm{~g} \mathrm{~m}^{-3}$. At OC5Me Chl $a>10 \mathrm{mg} \mathrm{m}^{-3}$, the over-estimate in OC4Me was not related to SPM which was between 2 and $8 \mathrm{~g} \mathrm{~m}^{-3}$. The offset between OC5Me and OC4Me was worse on the Thames compared to the Wash transects due to an increase in SPM adjacent to the Thames estuary. For OC5Me and AP2, 51\% of the variance between the two algorithms was explained, the slope was low $(\sim 0.58)$, the intercept was high (Table 3 ) and there was a large offset between the algorithms at both low and high Chl $a$ concentrations (Fig. 5B, E). There was a large error in AP2 Chl $a$ between 1 and $20 \mathrm{mg} \mathrm{m}^{-3}$ at both high $\left(>14 \mathrm{~g} \mathrm{~m}^{-3}\right.$ ) and low (2-3 $\mathrm{g} \mathrm{m}^{-3}$ ) non-algal SPM. The slope was lower on the Thames transect but the scatter was higher on the Wash transect (Fig. 5B, E, Table 3). Above $10 \mathrm{mg} \mathrm{m}^{-3} \mathrm{Chl} a$, the scatter between OC5Me and AP2 was reduced. Similarly, for OC4Me and AP2, 45\% of the variance was explained, the slope was low and the intercept was high (Table 3 ) and there was a large scatter between the two algorithms over the entire OC4 Chl $a$ range from $0.6-65.0 \mathrm{mg} \mathrm{m}^{-3}$. The offset and scatter between the algorithms was similar on both transects (Fig. 5C, F). The spatial and temporal differences between the algorithms are illustrated in satellite images during two different periods in spring (April 2010; Fig. 6) and summer (July 2011; Fig. 7). In coastal waters during both periods, OC5Me Chl $a<$ OC4Me Chl $a$, whereas in open ocean waters OC5Me and OC4Me were similar (Fig. 6) except in July 2011 when OC4Me > OC5Me (Fig. 7). By contrast, AP2 exhibited the lowest Chl $a$ in coastal regions of the North Sea and English Channel and did not yield data at all in some coastal and shelf areas (Figs. 6C, 7C). For GSM, in the coastal regions off Denmark, Holland, Belgium, northern France and the UK, Chl $a$ was higher than for OC5Me and OC4Me (Figs. 6D,
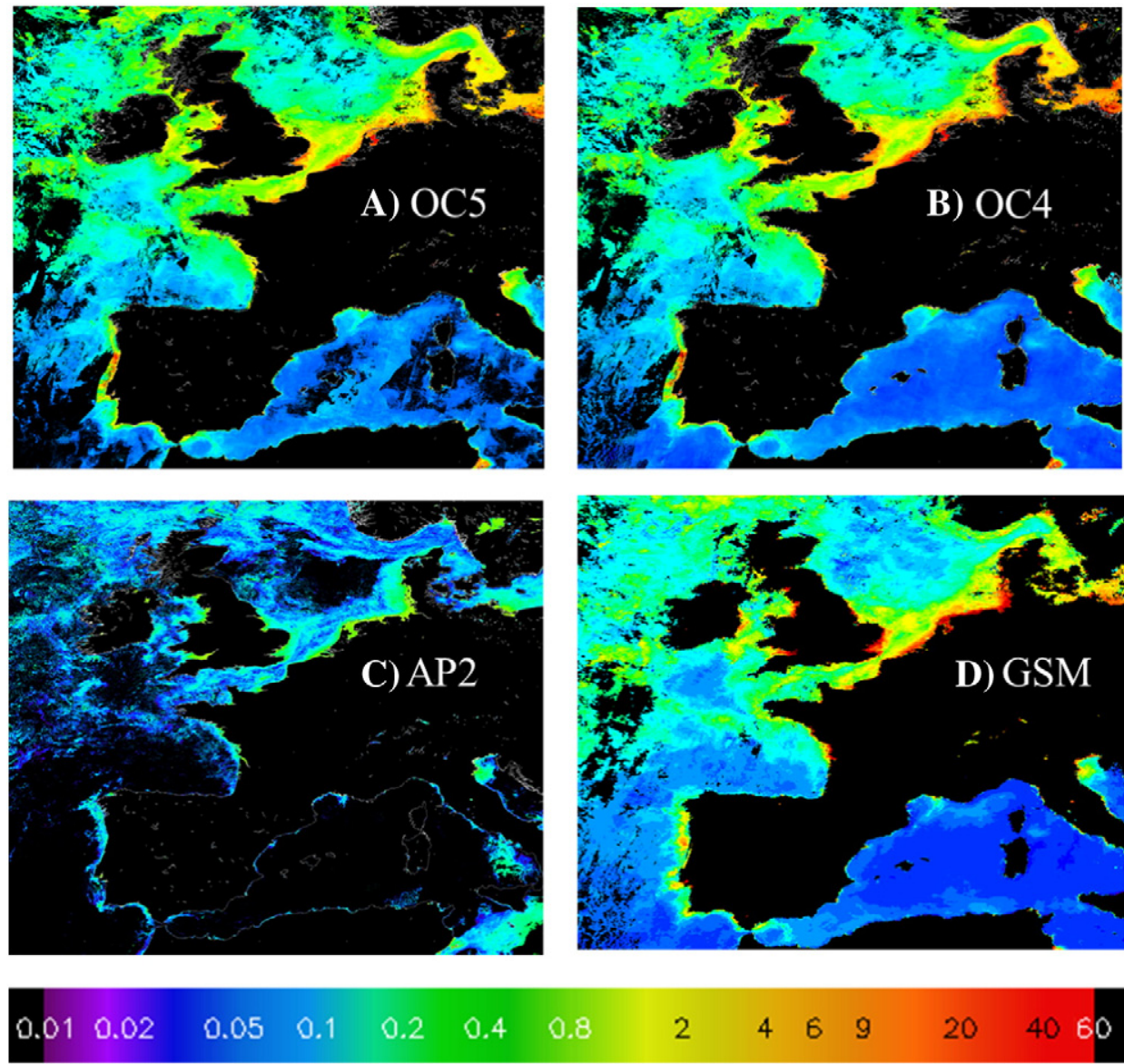

Fig. 7. Comparison of MERIS MEGS8.0 Chl a monthly composites of July 2011 using (A.) OC5Me, (B.) OC4Me, (C.) AP2, (D.) GSM. 
7D). In some offshore areas of the North Sea and Celtic Sea off SW England and southern Ireland, GSM Chl $a$ was lower, but in spring in the Bay of Biscay, off the west Irish Coast and central North Sea, GSM Chl $a$ was also higher. To highlight the spatial variability in the satellite images between the algorithms, Chl $a$ were extracted from the April 2010 images (Fig. 6) at every $10 \mathrm{~km}$ along transects from the Wash to the Schelde Estuary and from the English Channel to the Seine Estuary on the French coast (Fig. 1C). At the ends of the transects near to the UK coast, OC4Me Chl $a$ was 2 to 6 times higher than OC5Me (Fig. 8A, B, E, F). AP2 under-estimated Chl $a$ across the entire transect (Fig. 8C, G). GSM generally over-estimated Chl $a$ but the spatial trends were erratic with large oscillations between high and low Chl $a$ values over small spatial scales (Fig. 8D, H).

\section{Discussion}

\subsection{MERIS ocean colour algorithm accuracy assessment}

The principal objective of this study was to assess the performance of Chl $a$ algorithms, that are widely available to end users, with two different MERIS AC processors in North West European waters. In situ $R_{r s}$ were firstly used to test the algorithms in the absence of the MERIS AC model to indicate potential errors in the Chl $a$ algorithm alone rather than combined errors arising from the input MERIS $R_{r s}$ and the Chl $a$ algorithm. Using in situ $R_{r s}$, OC5Me, OC4Me and OC3Me had a similar slope, but OC5Me showed a higher scatter, illustrated by the higher $\mathrm{S}$ and $\mathrm{M}$ values compared to OC4Me and OC3Me (Table 2). This suggests that with in situ $R_{r s}$, OC4Me and OC3Me are the most accurate algorithms for the NW European region (Fig. 2B, D). The slope for GSM was closer to 1 , but the scatter from 0.5 to $20 \mathrm{mg} \mathrm{m}^{-3}$ was high (Fig. $2 C$ ) and this algorithm was the least accurate using in situ $R_{r s}$. It was
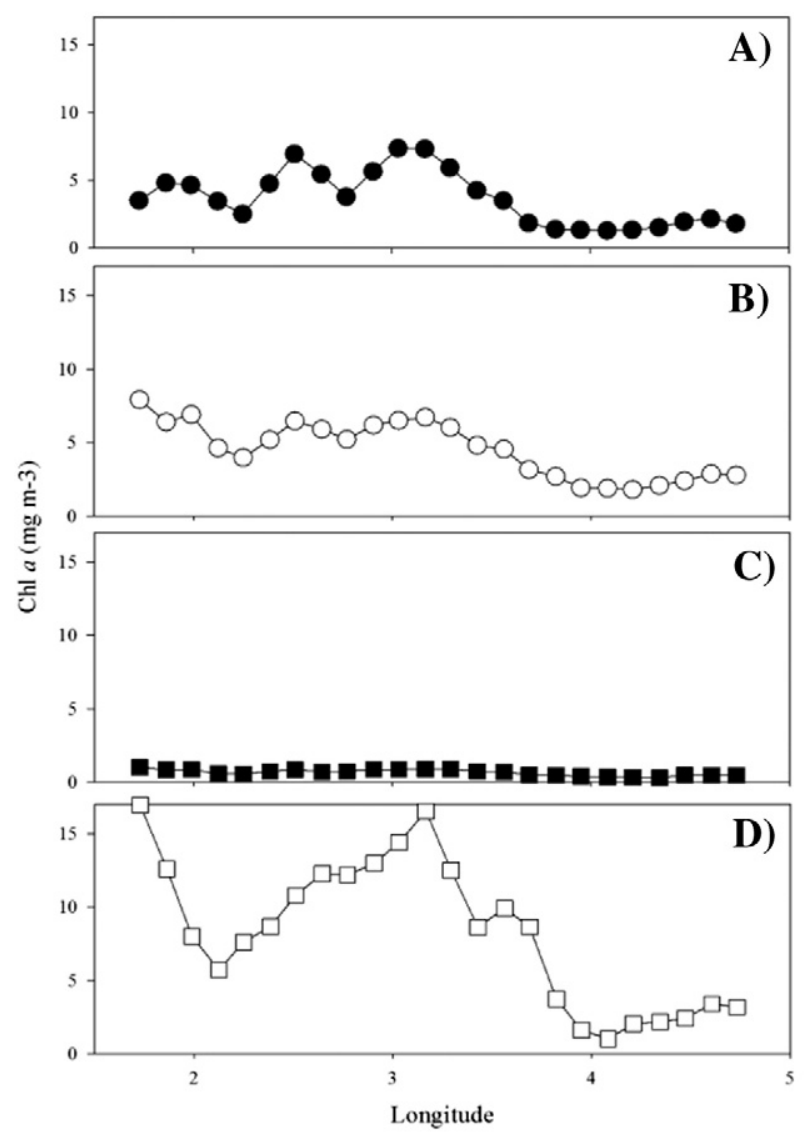

not possible to run AP2 with just in situ $R_{r s}$, since the AC is an integral part of the AP2 NN processor and is not available without the AC component of the model.

Secondly, both COASTCOLOUR and MEGS8.0 $R_{r s}$ were used to test the algorithms. We found that AP2 was the least accurate in these regions (Figs. 3C, 4C); AP2 had a large bias using both processors at low and high Chl $a$ concentrations, which is reflected in the high $\log _{10}$-RMS, S, $\mathrm{F}_{\min }$ and $\mathrm{F}_{\max }$ values (Table 2). When AP2 was processed as MEGS8.0 monthly composite images for European coastal regions, there were a large number of pixel drop-outs caused by none convergence in the NN (Figs. 6C, 7C). In addition, AP2 Chl $a$ values in both coastal and open ocean areas of the North Sea and Atlantic Ocean were significantly lower than those obtained from OC4Me and OC5Me (Figs. 6, 7, 8), which is reflected by the tendency to under-estimate Chl a shown in Figs. 3C, 4C.

The AP2 NN has been shown to be accurate in the North Sea (Doerffer and Schiller, 2007), but is not as accurate in the Adriatic (Zibordi et al., 2006a), Baltic (Attila et al., 2013), Mediterranean (Antoine et al., 2008) Seas, South African coastal and shelf waters (Smith et al., 2013), Siberian Arctic coastal and shelf waters (Heim et al., 2014), US coastal regions (Mishra and Mishra, 2012) and tropical coastal regions (Ambarwulan et al., 2010), especially when compared against standard MODIS-Aqua or SeaWiFS ocean colour products. In a number of studies the MERIS AP2 NN has been modified to account for the regional variation in IOPs which has improved it's performance (Attila et al., 2013; Smith et al., 2013). Alternative algorithms have been proposed for MERIS that have proven to be more accurate for the North Sea (Tilstone et al., 2012; Van der Woerd and Pasterkamp, 2008) and Iberian Peninsula (Gonzalez Vilas et al., 2011; Sa et al., 2015), but these are not widely available to end users. There is a tendency for MERIS AP2 in some coastal waters to under-estimate Chl $a$ in the
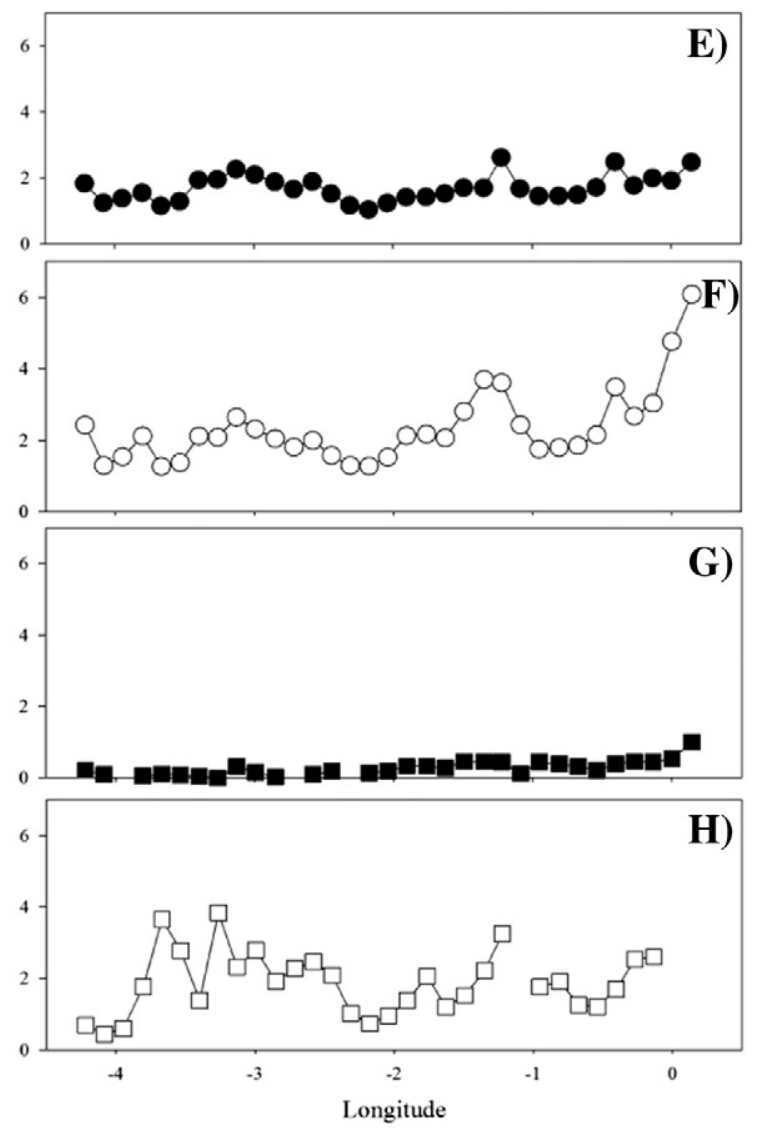

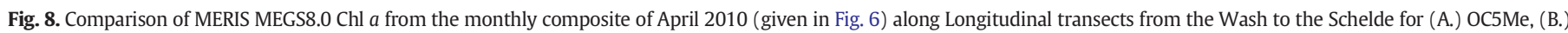

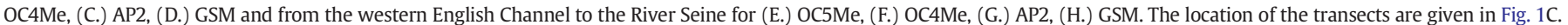


Table 3

Percentage variance explained $\left(\mathrm{R}^{2}\right)$, intercept and slope from linear regression between OC5Me, OC4Me and AP2 Chl $a$ along transects from the Schelde estuary to The Wash and the Thames to the Schelde estuaries (see Fig. 1C for details of transects).

\begin{tabular}{|c|c|c|c|c|c|c|}
\hline & $\mathrm{R}^{2}$ & Slope & Intercept & $\mathrm{R}^{2}$ & Slope & Intercept \\
\hline & \multicolumn{3}{|c|}{$\begin{array}{l}\text { The wash-schelde estuary } \\
\mathrm{N}=3734\end{array}$} & \multicolumn{3}{|c|}{$\begin{array}{l}\text { Thames-schelde estuaries } \\
\mathrm{N}=4042\end{array}$} \\
\hline OC5Me v OC4Me & 0.60 & 1.13 & 1.36 & 0.57 & 0.87 & 2.27 \\
\hline OC5Me v AP2 & 0.49 & 0.64 & 2.77 & 0.50 & 0.53 & 3.00 \\
\hline OC4Me v AP2 & 0.44 & 0.42 & 3.09 & 0.47 & 0.43 & 2.85 \\
\hline
\end{tabular}

range $<1 \mathrm{mg} \mathrm{m}^{-3}$ and to over-estimate $\mathrm{Chl} a$ at values $>6 \mathrm{mg} \mathrm{m}^{-3}$ (Tilstone et al., 2012). Knowing this bias in the algorithm, MERIS AP2 has under gone several rounds of re-calibration, which has resulted in re-processing the MERIS archive (Bourg et al., 2011). One of the problems experienced with the AP2 NN is that adding further training data can lead to 'over-training' which offers the algorithm further multiple possible solutions to retrieving IOPs, which may not necessarily result in accurate IOP spectra (IOCCG, 2006). From our analyses, the scatter plots indicated that COASTCOLOUR AP2 under- and over-estimates Chl $a$ in all regions tested and that MEGS8.0 AP2 under- and over-estimates Chl $a$ in the North Sea and English Channel, and under-estimates in the Mediterranean Sea and off the Portuguese coast (Figs. 3C, 4C). Analysis of the satellite imagery indicated that AP2 consistently under-estimated Chl $a$ in all regions (Figs. 6C, 7C, 8C, G).

By comparison, OC4Me was designed for global applications over optically deep ocean waters (Morel and Antoine, 2011). The retrieval accuracy of Chl $a$ by satellite ocean colour sensors is expected to be
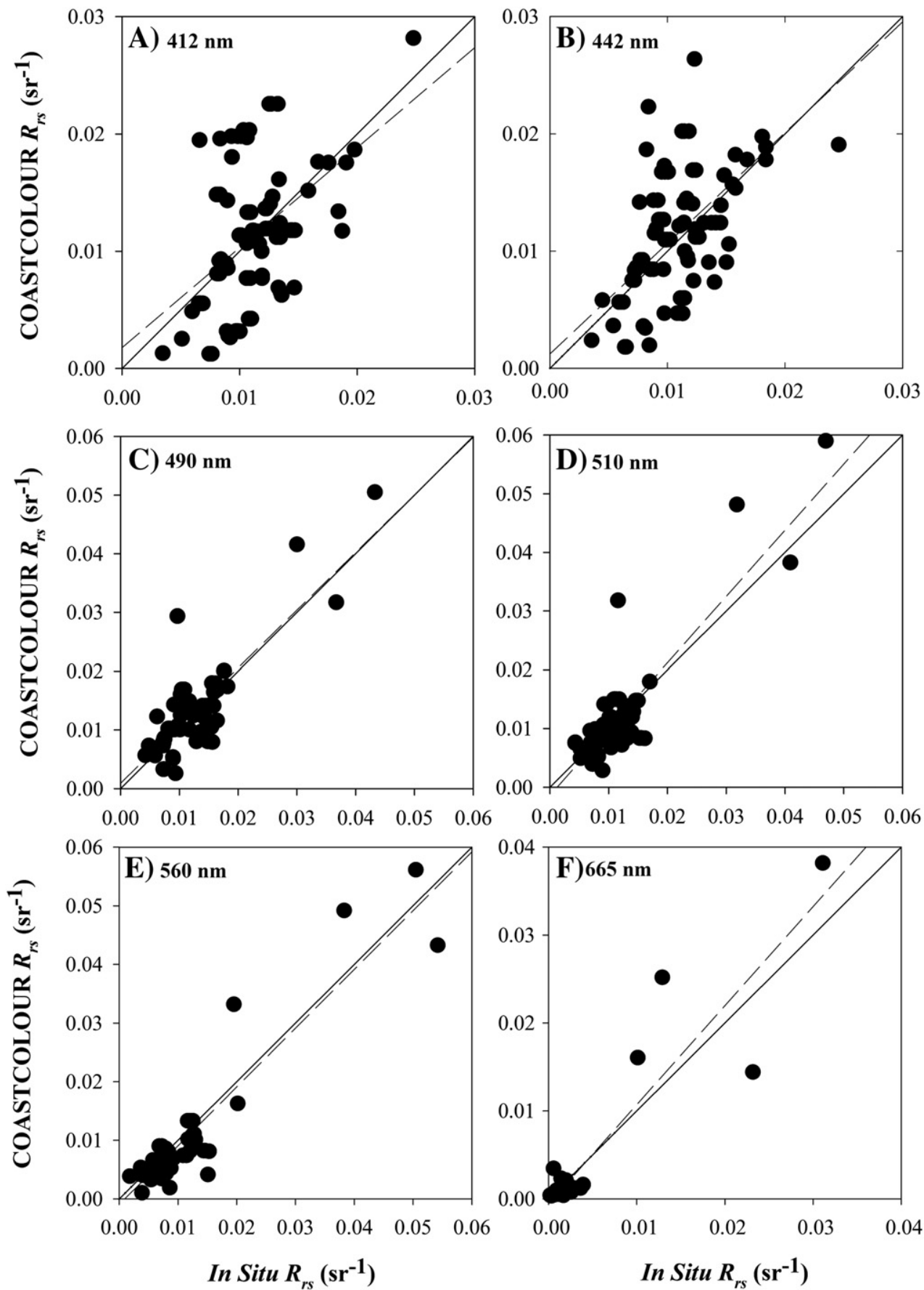

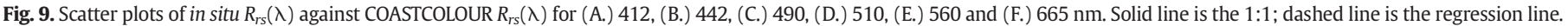


within $\pm 35 \%$ in oceanic waters (Bailey and Werdell, 2006; Blondeau-Patissier et al., 2014). This may not always be the case (Hu et al., 2000; Moore et al., 2009) and therefore may not be sufficient for the purpose of monitoring phytoplankotn biomass in the coastal zone. In the coastal waters tested, OC4Me consistently over-estimated Chl $a$ at values $>1 \mathrm{mg} \mathrm{m}^{-3}$ (Figs. 3B, 4B), though for the few match-ups with Chl $a>10 \mathrm{mg} \mathrm{m}^{-3}$, the retrieval accuracy improved. The use of these blue: blue-green band-ratios often leads to erroneous retrievals in coastal waters, where the optical complexity is highly variable (Blondeau-Patissier et al., 2004). The blue band can be affected by both the absorption of CDOM and scattering from SPM (Dierssen, 2010) and in turbid waters the blue-green band can be related to SPM more than to phytoplankton. Absorbing aerosols and the $a_{C D O M}$ can propagate as negative $n L_{w}$ at short wavelengths, which can result in an over-estimate of Chl $a$, as observed in coastal regions of the Bay of Bengal (Tilstone et al., 2011), United States (Cannizzaro et al., 2013; Le et al., 2013a), the Bering Sea (Naik et al., 2013), South-East Asia (Ahn and Shanmugam, 2006), the North Sea and Kattegat (Jorgensen, 2004). OC4 is often applied indiscriminately in some coastal waters (Dupouy et al., 2010), without a proper understanding of the potential errors that can be incurred in these waters. For the coastal and shelf environments tested in this study however, the relative difference between the in situ measurements and OC4Me over the entire Chl $a$ range was $\sim 25 \%$, and therefore within the accepted tolerance for Case 1 waters. OC4Me tended to over-estimate $\mathrm{Chl} a$ in coastal areas of the North Sea, English Channel and Portuguese coast (Figs. 3B, 4B, 8B, F).
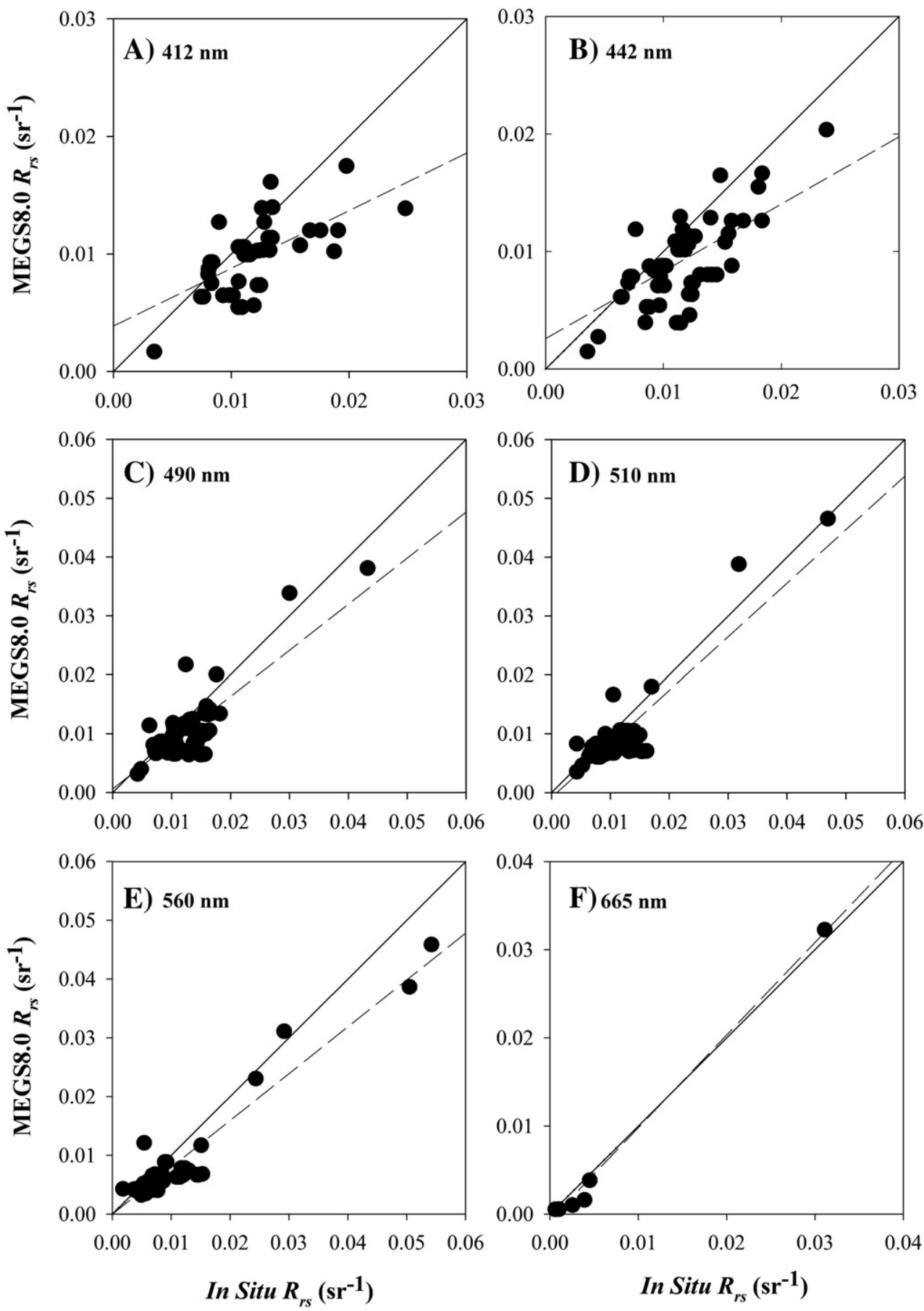

Fig. 10. Scatter plots of in situ $R_{r s}(\lambda)$ against MEGS8.0 $R_{r s}(\lambda)$ for (A.) 412, (B.) 442, (C.) 490, (D.) 510 , (E.) 560 and (F.) $665 \mathrm{~nm}$. Solid line is the $1: 1$; dashed line is the regression line. 

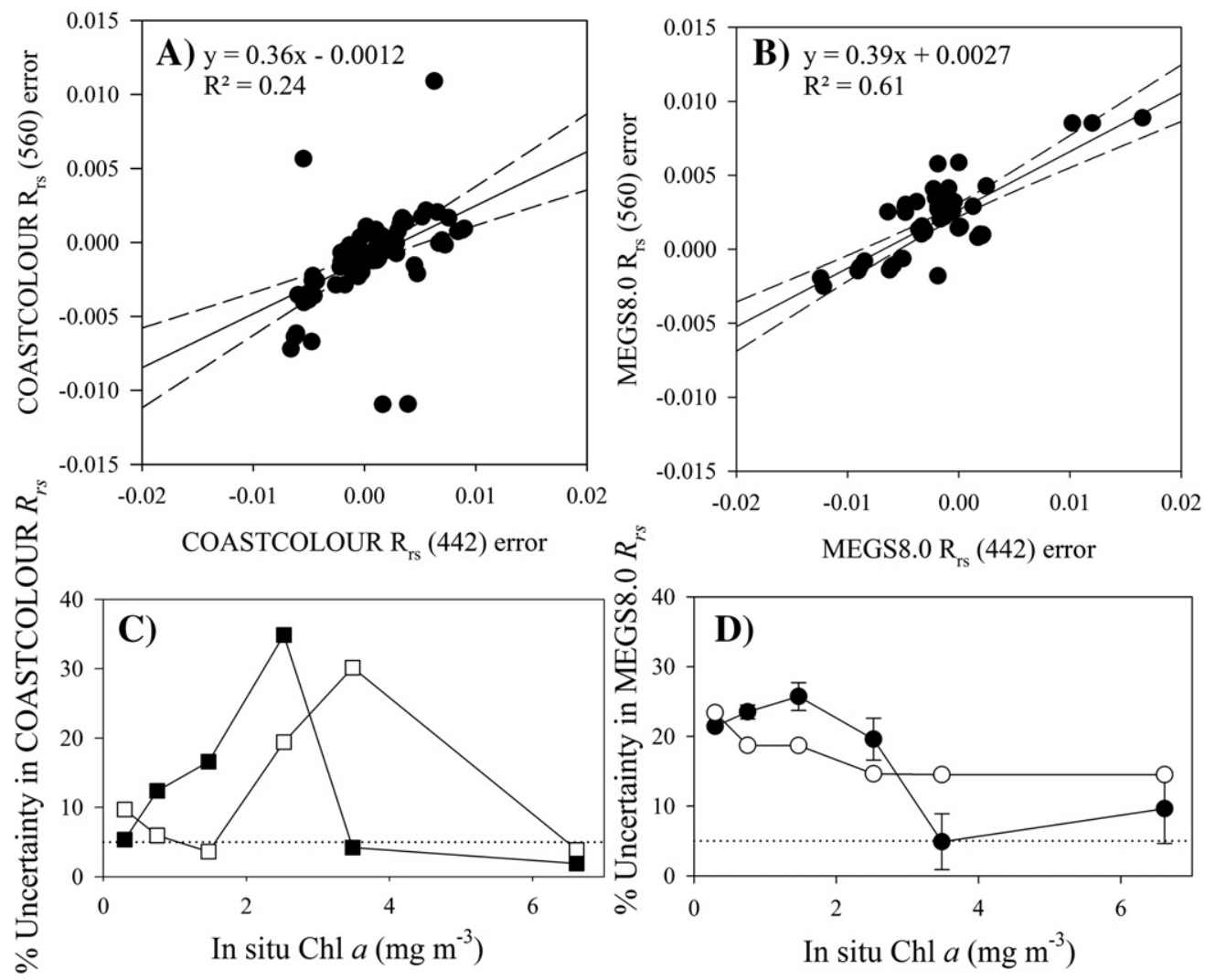

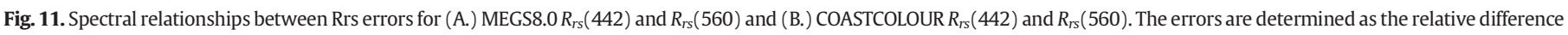

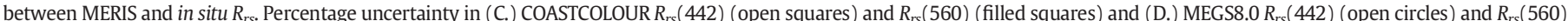

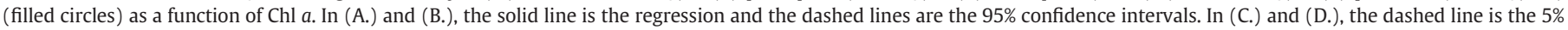
uncertainty limit.

The performance of OC3Me was similar to OC4Me, with the advantage of ommitting the $R_{r s}(412)$ band where the error is greatest (see Section 4.2). For OC3Me, of the $\sim 90$ satellite-in situ Chl $a$ match ups obtained with MEGS8.0 (Fig. 4D), 83\% of these used the $R_{r s}(490): R_{r s}(560)$ ratio. The $R_{r s}(442): R_{r s}(560)$ ratio was used to calculate Chl $a$ at stations predominantly from the Portuguese coast and Mediterranean Sea, which relate to those points below the $1: 1$ in Fig. 4D, where the under-estimate in $R_{r s}(442)$ (see Section 4.2) led to lower Chl $a$ concentrations. The high scatter in OC3Me Chl $a$ in the North Sea were predominantly at stations in the southern North Sea off the coast of France, principally due to an under-estimate in $R_{r s}(490)$ (see Section 4.2), which led to higher Chl $a$ values (Figs. 3D \& 4D).
The GSM algorithm had a slope close to 1 and a low intercept though there was a very high scatter for some of the match-up points, which resulted in high log-RMS and RPD (Figs. 3E, 4E). This was also reflected in the composite images from April 2010 (Fig. 6) and July 2011 (Fig. 7), which showed that GSM Chl $a$ was consistently higher in coastal regions and both lower and higher offshore compared with OC5Me and OC4Me. The GSM Chl $a$ extracted from transects in April 2010 in the North Sea and English Channel (Fig. 8D, H) indicate that the outliers in the scatter plot represent large areas of the image where GSM consistently over-estimate Chl $a$ (Fig. 8). The GSM is semi-analytical and was calibrated using the SeaBAM dataset (Maritorena et al., 2002) and like OC4, was originally developed for Case 1 waters. The GSM uses $R_{r s}(442)$ to

Table 4

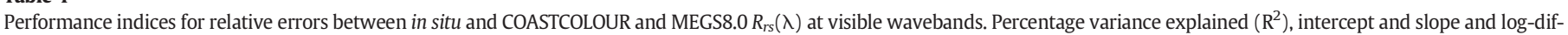
ference errors in measured and satellite Chla ratio as Mean $(M)$, Standard deviation $(S)$ and root-mean square ( $\log _{10}-\mathrm{RMS}_{\text {). }}$

\begin{tabular}{|c|c|c|c|c|c|c|c|c|c|c|c|c|c|}
\hline$\lambda$ & $\mathrm{N}$ & $\mathrm{R}^{2}$ & Slope & Intercept & $\mathrm{R}$ & RPD & $\log _{10}$-RMS & $\mathrm{M}$ & $\mathrm{S}$ & $F_{\text {med }}$ & $\mathrm{F}_{\max }$ & $\mathrm{F}_{\min }$ & RMS-E \\
\hline \multicolumn{14}{|c|}{ COASTCOLOUR } \\
\hline 412 & 98 & 0.53 & 1.14 & 0.004 & 1.02 & 0.67 & 0.25 & 0.05 & 0.25 & 1.11 & 1.98 & 0.62 & 0.005 \\
\hline 442 & 103 & 0.72 & 1.02 & -0.003 & 1.00 & 5.33 & 0.19 & 0.01 & 0.20 & 1.02 & 1.60 & 0.65 & 0.004 \\
\hline 490 & 101 & 0.65 & 0.98 & 0.0009 & 0.99 & 0.19 & 0.15 & -0.01 & 0.15 & 0.97 & 1.36 & 0.69 & 0.004 \\
\hline 510 & 101 & 0.61 & 1.23 & -0.002 & 1.01 & 16.98 & 0.13 & 0.01 & 0.13 & 1.03 & 1.39 & 0.77 & 0.004 \\
\hline 560 & 100 & 0.86 & 0.86 & 0.002 & 1.03 & 69.06 & 0.16 & 0.07 & 0.14 & 1.17 & 1.63 & 0.84 & 0.003 \\
\hline 665 & 91 & 0.76 & 1.28 & 0.0006 & 1.06 & 132.66 & 0.26 & 0.19 & 0.17 & 1.54 & 2.30 & 1.04 & 0.001 \\
\hline \multicolumn{14}{|c|}{ MEGS8.0 } \\
\hline 412 & 68 & 0.41 & 0.49 & 0.004 & 1.05 & -9.2 & 0.14 & 0.09 & 0.11 & 1.22 & 1.58 & 0.94 & 0.0005 \\
\hline 442 & 70 & 0.46 & 0.54 & 0.003 & 1.06 & -8.3 & 0.20 & 0.11 & 0.16 & 1.29 & 1.87 & 0.89 & 0.004 \\
\hline 490 & 94 & 0.63 & 0.78 & 0.0006 & 1.05 & -6.8 & 0.14 & 0.09 & 0.11 & 1.23 & 1.58 & 0.96 & 0.0007 \\
\hline 510 & 94 & 0.75 & 0.91 & -0.0008 & 1.05 & 2.8 & 0.14 & 0.09 & 0.10 & 1.23 & 1.56 & 0.98 & 0.001 \\
\hline 560 & 88 & 0.89 & 1.12 & 0.0009 & 1.05 & 32.5 & 0.15 & 0.11 & 0.10 & 1.27 & 1.62 & 1.00 & 0.0006 \\
\hline 665 & 18 & 0.99 & 1.05 & -0.0007 & 1.07 & 84.1 & 0.25 & 0.18 & 0.14 & 1.53 & 2.11 & 1.11 & 0.0003 \\
\hline
\end{tabular}


partition the absorption $a_{d g}(442)$ and $b_{b p}(442)$ and is calibrated using a simulated annealing procedure to retrieve $a_{p h}{ }^{*}(\lambda)$ at 412, 443, 488, 530 and $555 \mathrm{~nm}$. It solves $a_{p h}(\lambda)$ in the presence of SPM and $a_{C D O M}(\lambda)$ by using a constant exponential slope of CDOM $\left(\mathrm{S}_{\mathrm{CDOM}}\right)$ of $0.0206 \mathrm{~m}^{-1} \mathrm{~nm}^{-1}$, a power-law exponent for particulate backscattering $(\eta=1.03373)$ expressed as a function of Chl $a$ (Morel and Maritorena, 2001), and an optimized $a_{p h}{ }^{*}$ as a fixed value $\left[a_{p h}{ }^{*}(443)=0.05582\right.$ ]. This IOP parameterisation may not be appropriate for these European coastal waters; $\mathrm{S}_{\mathrm{CDOM}}$ used for calibrating the GSM is too high for the North Sea; $S_{C D O M}$ of 0.0101 and $0.0232 \mathrm{~m}^{-1} \mathrm{~nm}^{-1}$ have been reported for this area (Astoreca et al., 2009) and therefore $0.0206 \mathrm{~m}^{-1} \mathrm{~nm}^{-1}$ is towards the upper limit for these waters. Similarly the assigned $a_{p h}{ }^{*}(\lambda)$ is too low for the Celtic Sea and the English Channel which have mean values between 0.07 \& $0.09 \mathrm{mg} \mathrm{m}^{-2}$, respectively (Tilstone et al., 2012). With MEGS 8.0, the under-estimate in $R_{r s}(442)$ (Fig. 10B) will propagate into the partitioning of $a_{d g}(442)$ and $b_{b p}(442)$ and then to estimating $a_{p h}{ }^{*}(442)$, which resulted in an over-estimate in Chl $a$ (Fig. 4E). This was observed over the entire region particularly in coastal and shelf regions of the North Sea and English Channel in spring (Figs. 6D, 8D, H).

OC5 was initially developed to provide realistic maps of Chl $a$ for the turbid waters of the English Channel and the Bay of Biscay for validating biogeochemical model outputs (Menesguen et al., 2007). The first SeaWiFS OC4v4 products showed blooms in January 1998 in the English Channel, which never occur and therefore prevented the use of these products being used for model assessment. High SeaWiFS $R_{r s}$ in blue and green bands for this region during winter, due to an increase in scattering from SPM, caused the over-estimate OC4v $4 \mathrm{Chl} a$. The rationale for developing OC5 was therefore to provide more accurate estimates of Chl $a$ in turbid waters and to be as close as possible to OC4 Chl $a$ in Case 1 waters. By construction, OC5 Chl $a$ is always lower than OC4 Chl $a$, which makes its application in Case 1 waters less reliable (Marrec et al., 2015). In the shelf waters of the Celtic and North Seas for example, OC5Me was similar, but slightly lower than OC4Me (e.g. Figs. 6, 7, 8). Since OC5 is empirical and is calibrated using level 2 $R_{r s}(\lambda)$, when data from a specific satellite sensor or mission, reprocessing may be required before applying OC5 to different data sources (Morozov et al., 2010). This implies that when using $n L_{w}(\lambda)$ from MODIS, MERIS, merged MERIS-MODIS-SeaWiFS, Sentinel-3 or any variant of these with a different atmospheric correction model or with in situ $R_{r s}$ (as illustrated in Fig. 2A), OC5 would require a full re-parameterization. The necessity to re-parameterize OC5Me when using a different $n L_{w}(\lambda)$ source is illustrated in Fig. 2. Since the LUT for OC5Me was parameterized using MERIS $R_{r s}(\lambda)$, using in situ $R_{r s}(\lambda)$ to run the algorithm resulted in a high scatter at Chl $a>1 \mathrm{mg} \mathrm{m}^{-3}$ in the North Sea (Fig. 2A) and was the third most accurate algorithm after OC3Me and OC4Me. Despite these limitations, OC5 has proven to be accurate in a range of different coastal waters including the Ganges Delta in the Bay of Bengal (Tilstone et al., 2011), the Bay of Biscay (Novoa et al., 2012) and the Ligurian and Tyrrhenian Seas (Lapucci et al., 2012). In NW European waters OC5Me was the most accurate algorithm using both COASTCOLOUR and MEGS8.0 $R_{r s}(\lambda)$ over the range of 0.1 to $35.0 \mathrm{mg} \mathrm{m}^{-3} \mathrm{Chl}$ a. OC5Me was parameterised using the OC4Me maximum band ratio and $n L_{w}(412)$ and $n L_{w}(560)$ bands from MERIS data in the English Channel and Bay of Biscay, where Chl $a$ is 0.05 to $15 \mathrm{mg} \mathrm{m}^{-3}$, SPM are 0.1 to $10 \mathrm{~g} \mathrm{~m}^{-3}$ (Gohin et al., 2002) and $a_{C D O M}(375)$ is $0.02-$ $1.76 \mathrm{~m}^{-1}$ (Vantrepotte et al., 2007). The range in Chl $a$, SPM and $a_{d g}(442)$ in North Sea, Mediterranean Sea, Western English Channel and Portuguese waters was $0.13-25.13 \mathrm{mg} \mathrm{m}^{-3}$ Chl $a$; $0.001-$ $27.02 \mathrm{~g} \mathrm{~m}^{-3}$ SPM; $0.22-1.80 \mathrm{~m}^{-1} a_{d g}$ (442), which covers the OC5 parameterisation range. Since OC5 was originally parameterised using in situ data from the English Channel and the neighbouring Bay of Biscay, it is perhaps not surprising that OC5Me performed so well. Further testing of OC5Me in other coastal and shelf seas is necessary to assess the applicability of this algorithm globally and whether further parameterisation may be necessary for other water types. Other empirical algorithms such as red: NIR, red: green, fluorescent line height and normalized difference Chl $a$ index algorithms have been shown to be accurate with MERIS $R_{r S}$ in optically complex waters at Chl $a>10 \mathrm{mg} \mathrm{m}^{-3}$ (Gower et al., 2005; Le et al., 2013b; Mishra and Mishra, 2012; Moses et al., 2012), including freshwater Lakes (Binding et al., 2011; Gilerson et al., 2010). In future studies, it may be interesting to compare these algorithms against OC5Me for coastal and shelf environments.

\subsection{Causes of differences between MERIS Ocean colour algorithms}

To assess the performance of MERIS Chl $a$ algorithms in NW European waters, we firstly addressed the question; what is the accuracy of MERIS $R_{r s}(\lambda)$ derived from different AC processors? MEGS8.0 was designed for use in Case 1 and 2 waters and COASTCOLOUR was designed specifically for use Case 2 waters. We were therefore also able to address the question of whether AC algorithms developed for global water types are more accurate than those developed specifically for Case 2 waters? In Figs. 9 \& 10 in situ and COASTCOLOUR and MEGS8.0 $R_{r s}(\lambda)$ are compared at MERIS bands. In Fig. 11 the error between $R_{r S}(442)$ and $R_{r s}(560)$ for COASTCOLOUR and MEGS8.0 is compared and the uncertainty in these bands over the range of in situ Chl $a$ concentrations is given. The difference between in situ and COASTCOLOUR $R_{r s}(442)$ over the match-up dataset was $5 \%$ and $8 \%$ for MEGS8.0 (Figs. 9, 10; Table 4).

Recent studies based on continuous in situ measurement acquisition from towers or buoys have shown that MERIS over-estimates $n L_{w}(442)$ globally by 44\% (Maritorena et al., 2010) and at coastal sites in the Adriatic-Baltic by 39\% (Zibordi et al., 2009a; Zibordi et al., 2006b), in the Mediterranean by 36\% (Antoine et al., 2008) and in the Skagerrak by $40 \%$ (Sorensen et al., 2007), which suggest that both of these MERIS AC processors improve $R_{r s}(442)$ in NW European waters. At least $65 \%$ of the stations in the validation data set had SPM $>3.0 \mathrm{~g} \mathrm{~m}^{-3}$, which theoretically should not affect these AC processors since both the COASTCOLOUR NN and MEGS8.0 BP AC are optimized for turbid, highly scattering waters. At $R_{r s} 490,510$, and $560 \mathrm{~nm}$, the difference between in situ and MEGS8.0 and COASTCOLOUR $R_{r S}(\lambda)$ decreased and MEGS8.0 $R_{r s}(560)$ and the NN COASTCOLOUR processor showed a similar accuracy (Figs. 9, 10; Table 4). Though the slope was closer to 1 for COASTCOLOUR.

$R_{r s}(412), R_{r s}(442), R_{r s}(490)$ and $R_{r s}(510)$, compared to MEGS8.0, the scatter was higher which increased the bias and random error (Table 4). Similarly, Goyens et al. (2013) found that MODIS-Aqua with a NN AC model, performed better at blue bands in water masses influenced by SPM, compared to the standard MODIS-Aqua AC. For $R_{r s}(560)$, MEGS8.0 was more accurate than COASTOCOLOUR. For $R_{r s}(665)$, the RPD for both MEGS8.0 and COASTCOLOUR in these waters were higher than those reported both globally $(\sim 125 \%)$, in the Baltic and Adriatic ( $47 \%)$, the Mediterranean ( 70\%) and in the Skagerrak ( 40\%) (Antoine et al., 2008; Zibordi et al., 2006a), though for MEGS8.0 there were fewer points due to a high number of error flags raised. Fig. 11 shows the relationship between the error in $R_{r s}$ (calculated as the difference between MEGS8.0 or COASTCOLOUR $R_{r s}(\lambda)$ and in situ $R_{r s}(\lambda)$ ) at $R_{r s}(560)$ and $R_{r s}(442)$. For MEGS8.0, the error in $R_{r s}(560)$ varied by $>0.009 \mathrm{sr}^{-1}$, and for COASTCOLOUR the error was $>0.015 \mathrm{sr}^{-1}$, which is $\sim 4$ times higher than that reported for the global open ocean (Hu et al., 2013). By comparison, the error in $R_{r s}(442)$ was lower for COASTCOLOUR compared to MEGS8.0, though for both processors this was $>0.02 \mathrm{sr}^{-1}$ (Fig. 11A, B). The potential error from atmospheric

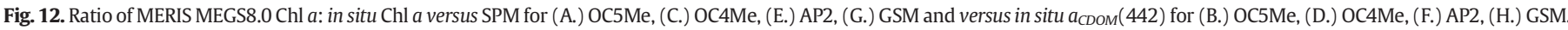

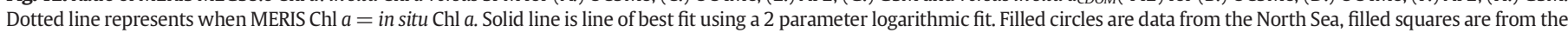
English Channel, open diamonds are from the Portuguese Shelf, open stars are the Mediterranean Sea. 

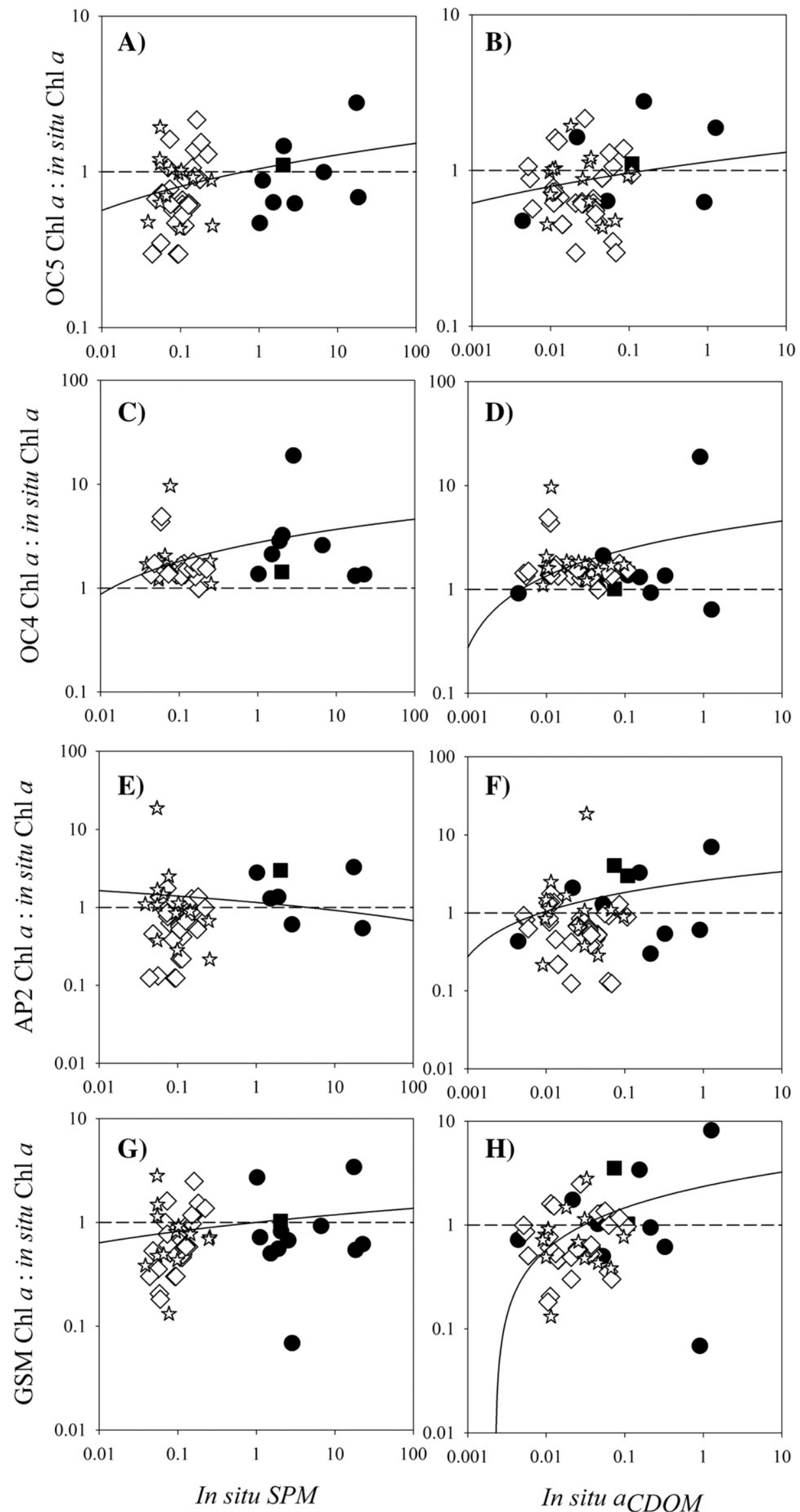
correction is estimated as $< \pm 0.0006 \mathrm{Sr}^{-1}$ for $R_{\mathrm{rs}}(443)$ in the global open ocean (Gordon et al., 1997). The error in $R_{r s}(\lambda)$ was therefore over an order of magnitude greater than the nominal error due to AC, indicating that other environmental effects (e.g. non-algal SPM backscattering, high absorption by CDOM, sun glint) contribute more to the errors in both MEGS8.0 and COASTCOLOUR $R_{r s}(442)$ (Fig. 11A, B). High uncertainty in $R_{r s}(\lambda)$ may be attributed to errors in the standard aerosol model of optical thickness used (Aznay and Santer, 2009) or failure in the correction at cloud borders (Gomez-Chova et al., 2007). The errors between COASTCOLOUR and MEGS8.0 $R_{r s}(560)$ and $R_{r s}(442)$ were correlated especially for MEGS8.0 (Fig. 11A, B), suggesting that it could be possible to predict the errors between these bands and systematically correct for them. For both COASTCOLOUR and MEGS8.0, the error in the $R_{r s}(560)$ band was less than half of the error at $R_{r s}(442)$ (Fig. 11A, $B)$. The differences reported in Table 4 provide an average uncertainty over the entire $R_{r s}(\lambda)$ match-up data set. The errors in ocean colour Chl $a$ however, may not always be uniform (Lee et al., 2010). For example, for SeaWiFS and MODIS-Aqua in oligotrophic regions of the Atlantic and Pacific Oceans over a Chl $a$ range of 0.05 to $0.2 \mathrm{mg} \mathrm{m}^{-3}$, Hu et al. (2013) reported an absolute accuracy of $<5 \%$ for $R_{r s}(\lambda)$ at blue bands for repeat satellite passes. For green and red bands the accuracy was $>5 \%$ and the uncertainty in both SeaWiFS and MODIS-Aqua $R_{r s}(\lambda)$ tended to increase with increasing Chl $a$. From MERIS match-ups with in situ $R_{r s}(\lambda)$, we found that the uncertainty in MEGS8.0 $R_{r s}(442)$ $(\sim 17 \%)$ was slightly higher than COASTCOLOUR $(\sim 12 \%)$ over a Chl $a$ range of 0.3 to $7 \mathrm{mg} \mathrm{m}^{-3}$ (Fig. 11D). At specific Chl $a$ concentrations however, there were large variations between the processors. Whilst the uncertainty for MEGS8.0 $R_{r S}(442)$ was fairly constant with increasing Chl $a$, for COASTCOLOUR $R_{r s}(442)$ the uncertainty was low from 0.3 to $1.5 \mathrm{mg} \mathrm{m}^{-3}$ and at $6.5 \mathrm{mg} \mathrm{m}^{-3}$, but then increased sharply between 2 and $4 \mathrm{mg} \mathrm{m}^{-3} \mathrm{Chl} a$ (Fig. 11D), reflecting the high scatter at the mid to upper range of $R_{r s}(442)$ values (Fig. 9B). For $R_{r s}(560)$, both MEGS8.0 and COASTCOLOUR processors exhibited a similar pattern, with low uncertainty at low and high $\mathrm{Chl} a$ concentrations, which for COASTCOLOUR were within the mission goal of absolute accuracy of $<5 \%$ (Fig. 11D). By comparison, the uncertainty in MEGS8.0 $R_{r s}(560)$ was $\sim 20 \%$ from 0 to $2.5 \mathrm{mg} \mathrm{m}^{-3}$ and $<5 \%$ at Chl $a>2.5 \mathrm{mg} \mathrm{m}^{-3}$. The net effect of these differences between AC processors is that when they are applied to a range of $\mathrm{Chl} a$ algorithms, MEGS8.0 proved to be slightly more accurate than COASTCOLOUR. Though the majority of the match-ups points were close to the coast (Fig. 1B), they potentially represent a mix of Case 1 waters along the Portugese coast, Celtic and Mediterrenean seas and Case 2 waters of the English Channel and North Sea. The ability of the MEGS8.0 processor to switch between the bright pixel and clear water AC models, means that it can be applied to a diverse range of water types typical of NW Europe from the coastal Atlantic Ocean and North Sea. By comparison, the COASTCOLOUR AC showed a higher scatter than MEGS8.0 at coastal Atlantic, Mediterranean and English Channel stations (Figs. 3, 4). Using MEGS8.0 OC5Me in these NW European waters, the target error tolerance for Chl $a$ is met (Table 2). These results have implications for the Sentinel-3 Ocean Colour Land Instrument (OLCI); the improved signal-to-noise ratio, long term radiometric stability and mitigation of sunglint and improvements in the AC for turbid and highly absorbing waters for OLCI, due to an increase in the number and position of spectral bands (Donlon et al., 2012), suggest that the accuracy of OC5 with OLCI could be improved further. Sentinel-3 OLCI will use the same or similar AC models that have been used for COASTCOLOUR and MEGS8.0 (Antoine 2010; Doerffer 2010; Moore and Lavender, 2010). Based on these results for MERIS, OC5 warrants further investigation with Sentinel-3 OLCI data.

Previous studies with SeaWiFS also found that accurate ocean colour estimates for the North Sea and English Channel can be achieved using the bright pixel AC in conjunction with band ratio $\mathrm{Chl} a$ algorithms (Blondeau-Patissier et al. 2004; Tilstone et al., 2013). This is facilitated by the use of the $R_{r s}(490): R_{r s}(560)$ ratio to derive Chl $a$ (Tilstone et al., 2013), since these bands are less affected by errors in the AC or due to high $a_{\text {СDOM }}(\lambda)$ absorption in the blue portion of the spectrum. Moore et al. (2009) assessed the uncertainty in Chl $a$ in eight optical water types classified on the shape of $R_{r s}(\lambda)$, and found that only in clear waters was the $35 \%$ mission error met. In turbid high sediment water types, the relative error increased to $>100 \%$. By comparison with MODIS-Aqua, the largest errors were encountered for water types dominated by phytoplankton and $\mathrm{a}_{\mathrm{CDOM}}$ (Goyens et al., 2013). Lee et al. (2010) used the theory of error propagation to derive the uncertainties in the inversion of inherent optical properties from $R_{r s}(\lambda)$ using the quasi analytical algorithm QAA (Werdell et al., 2013) with a simulated data set and found that the error in $a(440)$ was 13 to $37 \%$ over a range of $a_{\text {СDOM }}(440)$ from 0 to $2 \mathrm{~m}^{-1}$. We therefore also addressed the question; what is the effect of $a_{\text {СDOM }}(442)$ and non-algal SPM on the Chl $a$ algorithms? To assess this we plot in situ SPM and $a_{C D O M}(442)$ against the MEGS8.0 Chl $a$ : in situ Chl $a$ ratio for OC5Me, OC4Me, AP2 and GSM (Fig. 12). The horizontal dotted line represents where the algorithm $\mathrm{Chl} a$ equals in situ $\mathrm{Chl} a$ and data points above this line represent an over-estimate in algorithm Chl $a$, and points below the dotted line represent an under-estimate in Chl $a$. A significant correlation with SPM or $a_{C D O M}(442)$ would suggest that the under- or over-estimate in the Chl $a$ algorithm could be partially accounted for by these variables. For OC5Me there was a significant positive correlation with non-algal SPM $\left(F_{1,69}=6.91, P=0.011, \mathrm{R}^{2}=0.08\right.$; Fig. $\left.12 \mathrm{~A}\right)$, suggesting that with MEGS8.0 the over-estimate in Chl $a$ observed for this algorithm (Figs. 3A, 4A) was due to non-algal SPM. For GSM, there was a significant positive correlation between $a_{\text {CDOM }}(442)$ and algorithm: in situ Chl $a\left(\mathrm{GSM}-F_{1,72}=34.40, P<0.0001 \mathrm{R}^{2}=0.32\right.$; Fig. $12 \mathrm{H}$ ), suggesting that the over-estimate in Chl $a$ (Fig. $4 \mathrm{E}$ ) is due to $a_{C D O M}(442)$. For OC4Me, the over-estimate in Chl $a$ at $<10.0 \mathrm{mg} \mathrm{m}^{-3}$ (Fig. 4E) is due to non-algal SPM (Fig. 5A, D). The over-estimate in OC4Me at Chl $a>10.0 \mathrm{mg} \mathrm{m}^{-3}$ could be due to $a_{C D O M}(442)$, though there were not sufficient data points in Fig. 12D to verify this. There was no significant correlation between AP2 and SPM or $a_{C D O M}(442)$ suggesting that under- and over-estimate in AP2 Chl $a$ is due to random error in the algorithm.

\section{Conclusions}

An accuracy assessment of MERIS Chl $a$ in NW European waters, was conducted using MEGS8.0 and COASTCOLOUR processors with ocean colour algorithms that are widely available from the ESA NASA and NEODAAS. OC5Me Chl $a$ was more accurate than OC3Me, OC4Me, GSM and AP2 Chl $a$ using both COASTCOLOUR and MEGS8.0 processors, and MEGS8.0 OC5Me was slightly more accurate than COASTCOLOUR. Satellite images processed using MEGS8.0 $R_{r s}(\lambda)$ illustrated that OC4Me was 5 to 10 fold higher than OC5Me in coastal regions of the North Sea and English Channel, which was principally caused by errors in OC4Me that co-varied with SPM. The GSM was $>10$ times higher than OC5Me in these regions, which was caused by variations in $a_{\text {CDOM }}(442)$. AP2 was the least accurate algorithm in these waters.

The error and uncertainty in both MEGS8.0 and COASTCOLOUR $R_{r s}(442)$ and $R_{r s}(560)$ over a Chl $a$ range of 0.3 to $7 \mathrm{mg} \mathrm{m}^{-3}$, were higher than the mission goal of $5 \%$ for the global ocean. The lower uncertainty in MEGS8.0 $R_{r s}(560)$ and the higher error in COASTCOLOUR $R_{r s}(560)$ led to slightly more accurate $\mathrm{Chl} a$ for the ocean colour algorithms tested with MEGS8.0. The performance of OC5 with MERIS data warrants further investigation with Sentinel-3 OLCI data for NW European and similar coastal and shelf waters.

\section{Acknowledgements}

We thank the Masters and the Crews of RV Belgica and Quest for their help during sampling in the North Sea and at the Western English Channel Observatory. We are indebted to Kevin Ruddick for use of RBINS optical data in the North Sea and to David Antoine for use of BOUSSOLE 
LoV data in the Mediterranean Sea. We also thank the Natural Environment Research Council (NERC), Earth Observation Data Acquisition and Analysis Service (NEODAAS) at Plymouth Marine Laboratory for enabling us to process the MERIS images. G.H.T., S.M-H. and S.B.G. were supported by the Natural Environment Research Council's National Capability - The Western English Channel Observatory (WCO) under Oceans 2025, NEODAAS and by the European Union funded contract Information System on the Eutrophication of our Coastal Seas (ISECA) (Contract no. 07-027-FR-ISECA) funded by INTERREG IVA 2 Mers Seas Zeeen Cross-border Cooperation Programme 2007-2013. GHT was additionally funded by the European Space Agency contract SEOM - Extreme Case 2 waters (C2X) (4000113691/15/I-LG). A.B.C, C.S. and J.I. were supported by the AQUA-USERS project (EU 7th Framework Programme, Contract No 607325). We also thank two anonymous referees and the Editor-in-Chief for useful comments that significantly improved the manuscript.

\section{References}

Ahn, Y.-H., Shanmugam, P., 2006. Detecting the red tide algal blooms from satellite ocean color observations in optically complex Northeast-Asia Coastal waters. Remote Sens. Environ. 103, 419-437.

Ambarwulan, W., Mannaerts, C.M., van der Woerd, H.J., Salama, M.S., 2010. Medium resolution imaging spectrometer data for monitoring tropical coastal waters: a case study of Berau estuary, East Kalimantan, Indonesia. Geocarto Int. 25, 525-541.

Andersson, A., Jurgensone, I., Rowe, O.F., Simonelli, P., Bignert, A., Lundberg, E., Karlsson, J. 2013. Can humic water discharge counteract eutrophication in coastal waters? PLoS One 8.

Antoine, D., Morel, A., 1997. Atmospheric correction of the ocean color observations of the medium resolution imaging spectrometer (MERIS). Proceedings of the Society of Photo-optical Instrumentation Engineers 2963. SPIE, pp. 101-106.

Antoine, D., d'Ortenzio, F. Hooker, S.B., Becu, G., Gentili, B., Tailliez, D., Scott, A.J., 2008. Assessment of uncertainty in the ocean reflectance determined by three satellite ocean color sensors (MERIS, SeaWiFS and MODIS-A) at an offshore site in the Mediterranean Sea (BOUSSOLE project). J. Geophys. Res. Oceans 113, C07013. http://dx.doi.org/10.07010.01029/02007JC004472.

Antoine, D., 2010. OLCI Level 2: Algorithm Theoretical Basis Document - Atmospheric Correction over Case 1 waters. European Space Agency Doc. Ref. S3-L2-SD-03-C07LOV-ATBD.

Astoreca, R., Rousseau, V., Lancelot, C., 2009. Coloured dissolved organic matter (CDOM) in Southern North Sea waters: optical characterization and possible origin. Estuar. Coast. Shelf Sci. 85, 633-640.

Attila, J., Koponen, S., Kallio, K., Lindfors, A., Kaitala, S., Ylostalo, P., 2013. MERIS case II water processor comparison on coastal sites of the northern Baltic Sea. Remote Sens. Environ. 128, 138-149.

Aznay, O., Santer, R., 2009. MERIS atmospheric correction over coastal waters: validation of the MERIS aerosol models using AERONET. Int. J. Remote Sens. 30, 4663-4684.

Babin, M., Morel, A., Fournier-Sicre, V., Fell, F., Stramski, D., 2003a. Light scattering properties of marine particles in coastal and open ocean waters as related to the particle mass concentration. Limnol. Oceanogr. 48, 843-859.

Babin, M., Stramski, D., Ferrari, G.M., Claustre, H., Bricaud, A., Obolensky, G., Hoepffner, N., 2003b. Variations in the light absorption coefficients of phytoplankton, nonalgal particles, and dissolved organic matter in coastal waters around Europe. J. Geophys. Res. Oceans 108, C73211. http://dx.doi.org/10.73210.71029/72001JC000882.

Baez, J.C., Real, R., Lopez-Rodas, V., Costas, E., Enrique Salvo, A., Garcia-Soto, C., FloresMoya, A., 2014. The North Atlantic Oscillation and the Arctic Oscillation favour harmful algal blooms in SW Europe. Harmful Algae 39, 121-126.

Bailey, S.W., Werdell, P.J., 2006. A multi-sensor approach for the on-orbit validation of ocean color satellite data products. Remote Sens. Environ. 102, 12-23.

Barker, K., 2011. MERIS Optical Measurements Protocols. Part A: in situ water reflectance measurements. Report CO-SCI-ARG-TN-0008. European Space Agency.

Barlow, R.G., Cummings, D.G., Gibb, S.W., 1997. Improved resolution of mono- and divinyl chlorophylls $\mathrm{a}$ and $\mathrm{b}$ and zeaxanthin and lutein in phytoplankton extracts using reverse phase C-8 HPLC. Mar. Ecol. Prog. Ser. 161, 303-307.

Beltran-Abaunza, J.M., Kratzer, S., Brockmann, C., 2014. Evaluation of MERIS products from Baltic Sea coastal waters rich in CDOM. Ocean Sci. 10, 377-396.

Binding, C.E., Greenberg, T.A., Jerome, J.H., Bukata, R.P., Letourneau, G., 2011. An assessment of MERIS algal products during an intense bloom in Lake of the Woods. J. Plankton Res. 33, 793-806

Birk, S., Bonne, W., Borja, A., Brucet, S., Courrat, A., Poikane, S., Solimini, A., van de Bund W., Zampoukas, N., Hering, D., 2012. Three hundred ways to assess Europe's surface waters: an almost complete overview of biological methods to implement the Water Framework Directive. Ecol. Indic. 18, 31-41.

Blondeau-Patissier, D., Tilstone, G.H., Martinez-Vicente, V., Moore, G.F., 2004 Comparison of bio-physical marine products from SeaWiFS, MODIS and a bio-optical model with in situ measurements from Northern European waters. J. Opt. A Pure Appl. Opt. 6, 875-889.

Blondeau-Patissier, D., Gower, J.F.R., Dekker, A.G., Phinn, S.R., Brando, V.E., 2014. A review of ocean color remote sensing methods and statistical techniques for the detection, mapping and analysis of phytoplankton blooms in coastal and open oceans. Prog. Oceanogr. 123, 123-144.

Bourg, L., Lerebourg, C., Mazeran, C., Bruniquel, V „, Barker, K., Jackson, J., Kent, C., Lavender, S., Moore, G., Brockmann, C., Bouvet, M., Delwart, S., Goryl, P., Huot, J.P., Kwiatkowska,
E., Fisher, J., Ramon, D., Doerffer, R., Antoine, D., Zagolski, F., Santer, R., 2011. In: Lerebourg, C., Bruniquel, V. (Eds.), MERIS 3rd Data Reprocessing: Software and ADF Updates. ACRI, France.

Boyce, D.G., Lewis, M.R., Worm, B., 2010. Global phytoplankton decline over the past century. Nature 466, 591-596.

Brockmann, C., 2011. COASTCOLOUR prototype regional product report. Deliverable DEL20. European Space Agency.

Calbet, A., Sazhin, A.F., Nejstgaard, J.C., Berger, S.A., Tait, Z.S., Olmos, L., Sousoni, D., Isari, S., Martinez, R.A., Bouquet, J.-M., Thompson, E.M., Bamstedt, U., Jakobsen, H.H., 2014. Future climate scenarios for a coastal productive planktonic food web resulting in microplankton phenology changes and decreased trophic transfer efficiency. PLoS One 9.

Campbell, J., Antoine, D., Armstrong, R., Arrigo, K., Balch, W., Barber, R., Behrenfeld, M., Bidigare, R., Bishop, J., Carr, M.E., Esaias, W., Falkowski, P., Hoepffner, N., Iverson, R., Kiefer, D., Lohrenz, S., Marra, J., Morel, A., Ryan, J., Vedernikov, V., Waters, K., Yentsch, C., Yoder, J., 2002. Comparison of algorithms for estimating ocean primary production from surface chlorophyll, temperature, and irradiance. Glob. Biogeochem. Cycles 16 (art. no.-1035).

Cannizzaro, J.P., Hu, C., Carder, K.L., Kelble, C.R., Melo, N., Johns, E.M., Vargo, G.A., Heil, C.A., 2013. On the accuracy of SeaWiFS ocean color data products on the West Florida Shelf. J. Coast. Res. 29, 1257-1272.

Chang, N.-B., Imen, S., Vannah, B., 2015. Remote sensing for monitoring surface water quality status and ecosystem state in relation to the nutrient cycle: a 40-year perspective. Crit. Rev. Environ. Sci. Technol. 45, 101-166.

Cristina, S.V., Goela, P., Icely, J.D., Newton, A., Fragoso, B., 2009. Assessment of water-leaving reflectances of oceanic and coastal waters using MERIS satellite products off the southwest coast of Portugal. J. Coast. Res. 1479-1483.

Cristina, S.C.V., Moore, G.F., Fernandes Costa Goela, P.R., Icely, J.D., Newton, A., 2014. In situ validation of MERIS marine reflectance off the southwest Iberian Peninsula: assessment of vicarious adjustment and corrections for near-land adjacency. Int. J. Remote Sens. 35, 2347-2377.

Cui, T.W., Zhang, J., Tang, J.W., Sathyendranath, S., Groom, S., Ma, Y., Zhao, W., Song, Q.J., 2014. Assessment of satellite ocean color products of MERIS, MODIS and SeaWiFS along the East China coast (in the Yellow Sea and East China Sea). ISPRS J. Photogramm. Remote Sens. 87, 137-151.

Dierssen, H.M., 2010. Perspectives on empirical approaches for ocean color remote sensing of chlorophyll in a changing climate. Proc. Natl. Acad. Sci. U. S. A. 107, 17073-17078.

Doerffer, R., 2002. Protocols for the Validation of MERIS Water Products. European Space Agency (Doc. No. PO-TN-MEL-GS-0043).

Doerffer, R., Schiller, H., 2007. The MERIS case 2 water algorithm. Int. J. Remote Sens. 28, 517-535.

Doerffer, R., 2010. OLCI Level 2: Algorithm Theoretical Basis Document - Alternative Atmospheric Correction. European Space Agency Doc. Ref. S3-L2-SD-03-C17-GKSSATBD.

Donlon, C., Berruti, B., Buongiorno, A., Ferreira, M.H., Femenias, P., Frerick, J., Goryl, P., Klein, U., Laur, H., Mavrocordatos, C., Nieke, J., Rebhan, H., Seitz, B., Stroede, J., Sciarra, R., 2012. The global monitoring for environment and security (GMES) sentinel-3 mission. Remote Sens. Environ. 120, 37-57.

Dupouy, C., Neveux, J., Ouillon, S., Frouin, R., Murakami, H., Hochard, S., Dirberg, G., 2010. Inherent optical properties and satellite retrieval of chlorophyll concentration in the lagoon and open ocean waters of New Caledonia. Mar. Pollut. Bull. 61, 503-518.

Ferreira, J.G., Andersen, J.H., Borja, A., Bricker, S.B., Camp, J., da Silva, M.C., Garces, E., Heiskanen, A.-S., Humborg, C., Ignatiades, L., Lancelot, C., Menesguen, A., Tett, P., Hoepffner, N., Claussen, U., 2011. Overview of eutrophication indicators to assess environmental status within the European Marine Strategy Framework Directive. Estuar. Coast. Shelf Sci. 93, 117-131.

Fiuza, A.F.D., Demacedo, M.E., Guerreiro, M.R., 1982. Climatological space and time-variation of the Portuguese coastal upwelling. Oceanol. Acta 5, 31-40.

Folkestad, A., Pettersson, L.H., Durand, D.D., 2007. Inter-comparison of ocean colour data products during algal blooms in the Skagerrak. Int. J. Remote Sens. 28, 569-592.

Gilerson, A.A., Gitelson, A.A., Zhou, J., Gurlin, D., Moses, W., Ioannou, I., Ahmed, S.A., 2010. Algorithms for remote estimation of chlorophyll-a in coastal and inland waters using red and near infrared bands. Opt. Express 18, 24109-24125.

Glibert, P.M., Allen, J.I., Artioli, Y., Beusen, A., Bouwman, L., Harle, J., Holmes, R., Holt, J., 2014. Vulnerability of coastal ecosystems to changes in harmful algal bloom distribution in response to climate change: projections based on model analysis. Glob. Chang. Biol. 20, 3845-3858.

Goela, P.C., Danchenko, S., Icely, J.D., Lubian, L.M., Cristina, S., Newton, A., 2014. Using CHEMTAX to evaluate seasonal and interannual dynamics of the phytoplankton community off the South-west coast of Portugal. Estuar. Coast. Shelf Sci. 151, 112-123.

Goela, P.C. Icely, J., Cristina, S., Danchenko, S, DelValls, T A, Newton, A. 2015. Using biooptical parameters as a tool for detecting changes in the phytoplankton community (SW Portugal). Estuar. Coast. Shelf Sci. 167, 125-137.

Gohin, F., 2011. Annual cycles of chlorophyll-a, non-algal suspended particulate matter, and turbidity observed from space and in-situ in coastal waters. Ocean Sci. 7, 705-732.

Gohin, F., Druon, J.N., Lampert, L., 2002. A five channel chlorophyll concentration algorithm applied to SeaWiFS data processed by SeaDAS in coastal waters. Int. J. Remote Sens. 23, 1639-1661

Gohin, F., Loyer, S., Lunven, M., Labry, C., Froidefond, J.M., Delmas, D., Huret, M., Herbland, A., 2005. Satellite-derived parameters for biological modelling in coastal waters: illustration over the eastern continental shelf of the Bay of Biscay. Remote Sens. Environ. $95,29-46$.

Gomez-Chova, L., Camps-Valls, G., Calpe-Maravilla, J., Guanter, L., Moreno, J., 2007. Cloudscreening algorithm for ENVISAT/MERIS multispectral images. IEEE Trans. Geosci. Remote Sens. 45, 4105-4118. 
Gonzalez Vilas, L., Spyrakos, E., Torres Palenzuela, J.M., 2011. Neural network estimation of chlorophyll a from MERIS full resolution data for the coastal waters of Galician rias (NW Spain). Remote Sens. Environ. 115, 524-535.

Gordon, H.R., Du, T., Zhang, T.M., 1997. Remote sensing of ocean color and aerosol properties: resolving the issue of aerosol absorption. Appl. Opt. 36, 8670-8684.

Gower, J., King, S., Borstad, G., Brown, L., 2005. Detection of intense plankton blooms using the $709 \mathrm{~nm}$ band of the MERIS imaging spectrometer. Int. J. Remote Sens. 26, 2005-2012.

Goyens, C., Jamet, C., Schroeder, T., 2013. Evaluation of four atmospheric correction algorithms for MODIS-aqua images over contrasted coastal waters. Remote Sens. Environ. 131, 63-75.

Grizzetti, B., Bouraoui, F., Aloe, A., 2012. Changes of nitrogen and phosphorus loads to European seas. Glob. Chang. Biol. 18, 769-782.

Groom, S., Martinez-Vicente, V., Fishwick, J., Tilstone, G., Moore, G., Smyth, T., Harbour, D., 2009. The Western English Channel observatory: optical characteristics of station L4. J. Mar. Syst. 77, 278-295.

Heim, B., Abramova, E., Doerffer, R., Guenther, F., Hoelemann, J., Kraberg, A., Lantuit, H. Loginova, A., Martynov, F., Overduin, P.P., Wegner, C., 2014. Ocean colour remote sensing in the southern Laptev Sea: evaluation and applications. Biogeosciences 11 , 4191-4210.

Hokedal, J., Aas, E., Sorensen, K., 2005. Spectral optical and bio-optical relationships in the Oslo Fjord compared with similar results from the Baltic Sea. Int. J. Remote Sens. 26, 371-386.

Hommersom, A., Peters, S., Wernand, M.R., de Boer, J., 2009. Spatial and temporal variability in bio-optical properties of the Wadden Sea. Estuar. Coast. Shelf Sci. 83, 360-370.

Hu, C.M., Carder, K.L., Muller-Karger, F.E., 2000. Atmospheric correction of SeaWiFS imagery over turbid coastal waters: a practical method. Remote Sens. Environ. 74, 195-206.

Hu, C.M., Feng, L., Lee, Z., 2013. Uncertainties of SeaWiFS and MODIS remote sensing reflectance: implications from clear water measurements. Remote Sens. Environ. 133, $168-182$.

IOCCG, 2000. Remote sensing of ocean colour in coastal and other optically-complex waters. In: Sathyendranath, S., Stuart, V. (Eds.), IOCCG Report. Bedford Institute of Oceanography, Canada, pp. 1-137.

IOCCG, 2006. Remote sensing of inherent optical properties: fundamentals, tests of algorithms and applications. In: Lee, Z.P. (Ed.), IOCCG Report 6. Dartmouth, Canada.

Jeffrey, S.W., Mantoura, R.F.C., Wright, S.W., 1997. Phytoplankton Pigments in Oceanography. UNESCO, Paris.

Jorgensen, P.V., 2004. SeaWiFS data analysis and match-ups with in situ chlorophyll concentrations in Danish waters. Int. J. Remote Sens. 25, 1397-1402.

Kou, L., Labrie, D., Chýlek, P., 1993. Refractive indices of water and ice the 0.65- to 2.5- $\mu \mathrm{m}$ spectral range. Appl. Opt. 32, 3531-3540.

Lapucci, C., Rella, M.A., Brandini, C., Ganzin, N., Gozzini, B., Maselli, F., Massi, L., Nuccio, C., Ortolani, A., Trees, C., 2012. Evaluation of empirical and semi-analytical chlorophyll algorithms in the Ligurian and North Tyrrhenian Seas. J. Appl. Remote. Sens. 6.

Le, C., Hu, C., Cannizzaro, J., Duan, H., 2013a. Long-term distribution patterns of remotely sensed water quality parameters in Chesapeake Bay. Estuar. Coast. Shelf Sci. 128, 93-103.

Le, C.F., Hu, C.M., Cannizzaro, J., English, D., Muller-Karger, F., Lee, Z., 2013b. Evaluation of chlorophyll-a remote sensing algorithms for an optically complex estuary. Remote Sens. Environ. 129, 75-89.

Lee, Z., Arnone, R., Hu, C., Werdell, P.J., Lubac, B., 2010. Uncertainties of optical parameters and their propagations in an analytical ocean color inversion algorithm. Appl. Opt. 49, 369-381.

Lerebourg, C., Mazeran, C., Huot, J.P., Antoine, D., 2011. Vicarious adjustment of the MERIS ocean colour radiometry. MERIS ATBD 2.24. European Space Agency.

Lorenzen, C.J., 1967. Determination of chlorophyll and pheo-pigments: spectrophotometric equations. Limnol. Oceanogr. 12, 343-347.

Maritorena, S., Siegel, D.A., Peterson, A.R., 2002. Optimization of a semianalytical ocean color model for global-scale applications. Appl. Opt. 41, 2705-2714.

Maritorena, S., d'Andon, O.H.F., Mangin, A., Siegel, D.A., 2010. Merged satellite ocean color data products using a bio-optical model: characteristics, benefits and issues. Remote Sens. Environ. 114, 1791-1804.

Marrec, P., Cariou, T., Mace, E., Morin, P., Salt, L.A., Vernet, M., Taylor, B., Paxman, K., Bozec Y., 2015. Dynamics of air-sea CO2 fluxes in the northwestern European shelf based on voluntary observing ship and satellite observations. Biogeosciences 12, 5371-5391.

McQuatters-Gollop, A., Raitsos, D.E., Edwards, M., Pradhan, Y., Mee, L.D., Lavender, S.J., Attrill, M.J., 2007. A long-term chlorophyll data set reveals regime shift in North Sea phytoplankton biomass unconnected to nutrient trends. Limnol. Oceanogr. 52, 635-648.

Melin, F., Zibordi, G., Berthon, J.-F., 2007. Assessment of satellite ocean color products at a coastal site. Remote Sens. Environ. 110, 192-215.

Menesguen, A., Cugier, P., Loyer, S., Vanhoutte-Brunier, A., Hoch, T., Guillaud, J.-F., Gohin, F., 2007. Two- or three-layered box-models versus fine 3D models for coastal ecological modelling? A comparative study in the English Channel (Western Europe). J. Mar. Syst. 64, 47-65.

Mishra, S., Mishra, D.R., 2012. Normalized difference chlorophyll index: a novel model for remote estimation of chlorophyll-a concentration in turbid productive waters. Remote Sens. Environ. 117, 394-406.

Mobley, C.D., 1999. Estimation of the remote sensing reflectance from above-surface measurements. Appl. Opt. 38, 7442-7455.

Moore, G., Lavender, S., 2010. Sentinel-3 optical products and algorithm definition. OLCl Bright Waters AC (Mesotrophic to High Turbidity). European Space Agency: BioOptika.

Moore, T.S., Campbell, J.W., Dowell, M.D., 2009. A class-based approach to characterizing and mapping the uncertainty of the MODIS ocean chlorophyll product. Remote Sens. Environ. 113, 2424-2430.
Morel, A., Antoine, D., 2011. Pigment Index Retrieval in Case 1 waters. Algorithm Technical Baseline Document 2.9. European Space Agency.

Morel, A., Maritorena, S., 2001. Bio-optical properties of oceanic waters: a reappraisal. J. Geophys. Res. C: Oceans 106, 7163-7180.

Morozov, E., Korosov, A., Pozdnyakov, D., Pettersson, L., Sychev, V., 2010. A new area-specific bio-optical algorithm for the Bay of Biscay and assessment of its potential for SeaWiFS and MODIS/aqua data merging. Int. J. Remote Sens. 31, 6541-6565.

Moses, W.J., Gitelson, A.A., Berdnikov, S., Saprygin, V., Povazhnyi, V., 2012. Operationa MERIS-based NIR-red algorithms for estimating chlorophyll-a concentrations in coastal waters-the Azov Sea case study. Remote Sens. Environ. 121, 118-124.

Mueller, J.L., 2000. Above-water radiance and remote sensing reflectance measurements and analysis protocols. In: Fargion, G.S., Mueller, J.L. (Eds.), Ocean Optics Protocols for Satellite Ocean Color Sensor Validation. National Aeronautical and Space Administration, Washingotn, USA.

Naik, P., D'Sa, E.J., Gomes, H.D.R., Goes, J.I., Mouw, C.B., 2013. Light absorption properties of southeastern Bering Sea waters: analysis, parameterization and implications for remote sensing. Remote Sens. Environ. 134, 120-134.

Nechad, B., Ruddick, K., Schroeder, T., Oubelkheir, K., Blondeau-Patissier, D., Cherukuru, N. Brando, V., Dekker, A., Clementson, L., Banks, A.C., Maritorena, S., Werdell, P.J., Sa, C., Brotas, V., Caballero de Frutos, I., Ahn, Y.H., Salama, S., Tilstone, G., MartinezVicente, V., Foley, D., McKibben, M., Nahorniak, J., Peterson, T., Silio-Calzada, A., Roettgers, R., Lee, Z., Peters, M., Brockmann, C., 2015. CoastColour Round Robin data sets: a database to evaluate the performance of algorithms for the retrieval of water quality parameters in coastal waters. Earth Syst. Sci. Data 7, 319-348.

Novoa, S., Chust, G., Sagarminaga, Y., Revilla, M., Borja, A., Franco, J., 2012. Water quality assessment using satellite-derived chlorophyll-a within the European directives, in the southeastern Bay of Biscay. Mar. Pollut. Bull. 64, 739-750.

Ohde, T., Siegel, H., Gerth, M., 2007. Validation of MERIS level-2 products in the Baltic Sea, the Namibian coastal area and the Atlantic Ocean. Int. J. Remote Sens. 28, 609-624.

O'Reilly, J.E., Maritorena, S., O'Brien, M.C., Siegel, D.A., Toole, D., Menzies, D., Smith, R.C., Mueller, J.L., Mitchell, B.G., Kahru, M., Chavez, F.P., Strutton, P., Cota, G.F., Hooker S.B., McClain, C.R., Carder, K.L., Muller-Karger, F., Harding, L., Magnuson, A., Phinney, D., Moore, G.F., Aiken, J., Arrigo, K.R., Letelier, R., Culver, M., 2000. Volume 11, SeaWiFS postlaunch calibration and validation analyses, part 3. NASA Tech. Memo. 1-49.

Palmer, S.C.J., Hunter, P.D., Lankester, T., Hubbard, S., Spyrakos, E., Tyler, A.N., Presing, M., Horvath, H., Lamb, A., Balzter, H., Toth, V.R., 2015. Validation of Envisat MERIS algorithms for chlorophyll retrieval in a large, turbid and optically-complex shallow lake. Remote Sens. Environ. 157, 158-169.

Peters, S.W.M., Eleveld, M., Pasterkamp, R., van der Woerd, H., Devolder, M., Jans, S., Park, Y., Ruddick, K., Block, T., Brockmann, C., Doerffer, R., Krasemann, H., Rottgers, R., Schonfeld, W., Jorgensen, P.V., Tilstone, G.H., Martinez-Vicente, V., Moore, G. Sorensen, K., Hokedal, J., Johnsen, T.M., Lomsland, E.R., Aas, E., 2005. An Atlas of Chlorophyll-a Concentrations for the North Sea Based on MERIS Imagery of 2003. Vrije Universiteit, Amsterdam, Amsterdam, The Netherlands.

Pope, R., Fry, E., 1997. Absorption spectrum (380-700 nm) of pure water. II. Integrating cavity measurements. Appl. Opt. 36, 8710-8722.

Reid, P.C., Taylor, A.H., Stephens, J.A., 1988. The Hydrography and Hydrographic Balanaces of the North Sea. Springer-Verlag, Berlin, Heidelberg, New York, London, Paris, Tokyo.

Romero, E., Garnier, J., Lassaletta, L., Billen, G., Le Gendre, R., Riou, P., Cugier, P., 2013. Large-scale patterns of river inputs in southwestern Europe: seasonal and interannual variations and potential eutrophication effects at the coastal zone. Biogeochemistry 113, 481-505.

Ruddick, K.G., De Cauwer, V., Park, Y.J., Moore, G., 2006. Seaborne measurements of near infrared water-leaving reflectance: the similarity spectrum for turbid waters. Limnol. Oceanogr. 51, 1167-1179.

Sa, C., D'Alimonte, D., Brito, A.C., Kajiyama, T., Mendes, C.R., Vitorino, J., Oliveira, P.B., da Silva, J.C.B., Brotas, V., 2015. Validation of standard and alternative satellite oceancolor chlorophyll products off Western Iberia. Remote Sens. Environ. 168, 403-419.

Saulquin, B., Gohin, F., Garrello, R., 2011. Regional objective analysis for merging high-resolution MERIS, MODIS/aqua, and SeaWiFS chlorophyll-a data from 1998 to 2008 on the European Atlantic Shelf. IEEE Trans. Geosci. Remote Sens. 49, 143-154.

Schiller, H., Doerffer, R., 2005. Improved determination of coastal water constituent concentrations from MERIS data. IEEE Trans. Geosci. Remote Sens. 43, 1585-1591.

Siegel, D.A., Buesseler, K.O., Doney, S.C., Sailley, S.F., Behrenfeld, M.J., Boyd, P.W., 2014 Global assessment of ocean carbon export by combining satellite observations and food-web models. Glob. Biogeochem. Cycles 28, 181-196.

Smith, M.E., Bernard, S., O'Donoghue, S., 2013. The assessment of optimal MERIS ocean colour products in the shelf waters of the KwaZulu-Natal Bight, South Africa. Remote Sens. Environ. 137, 124-138.

Sorensen, K., Aas, E., Hokedal, J., 2007. Validation of MERIS water products and bio-optical relationships in the Skagerrak. Int. J. Remote Sens. 28, 555-568.

Tilstone, G.H., Moore, G.F., Sorensen, K., Doerffer, R., Rottgers, R., Ruddick, K.G., Jorgensen, P.V., Pasterkamp, R., 2004. Regional Validation of MERIS Chlorophyll products in North Sea coastal waters: REVAMP protocols. ENVISAT validation Workshop. European Space Agency, Frascatti, Italy (http://envisat.esa.int/workshops/mavt_2003/ MAVT-2003_802_REVAMPprotocols3.pdf)

Tilstone, G.H., Angel-Benavides, I.M., Pradhan, Y., Shutler, J.D., Groom, S., Sathyendranath, S., 2011. An assessment of chlorophyll-a algorithms available for SeaWiFS in coastal and open areas of the Bay of Bengal and Arabian Sea. Remote Sens. Environ. 115, 2277-2291

Tilstone, G.H., Peters, S.W.M., van der Woerd, H.J., Eleveld, M.A., Ruddick, K., Schoenfeld W., Krasemann, H., Martinez-Vicente, V., Blondeau-Patissier, D., Roettgers, R. Sorensen, K., Jorgensen, P.V., Shutler, J.D., 2012. Variability in specific-absorption properties and their use in a semi-analytical ocean colour algorithm for MERIS in North Sea and Western English Channel Coastal Waters. Remote Sens. Environ. 118, 320-338. 
Tilstone, G.H., Lotliker, A.A., Miller, P.I., Ashraf, R.M., Kumar, T.S., Suresh, T., Ragavan, B.R Menon, H.B., 2013. Assessment of MODIS-aqua chlorophyll-a algorithms in coastal and shelf waters of the eastern Arabian Sea. Cont. Shelf Res. 65, 14-26.

Van der Linde, D., 1998. Protocol for Total Suspended Matter Estimate. JRC.

van der Woerd, H., Pasterkamp, R., 2004. Mapping of the North Sea turbid coastal waters using SeaWiFS data. Can. J. Remote. Sens. 30, 44-53.

Van der Woerd, H.J., Pasterkamp, R., 2008. HYDROPT: a fast and flexible method to retrieve chlorophyll-a from multispectral satellite observations of optically complex coastal waters. Remote Sens. Environ. 112, 1795-1807.

Valente, A.S., da Silva, J.C.B., 2009. On the observability of the fortnightly cycle of the Tagus estuary turbid plume using MODIS ocean colour images. J. Mar. Syst. 75, 131-137.

Vantrepotte, V., Brunet, C., Meriaux, X., Lecuyer, E., Vellucci, V., Santer, R., 2007. Bio-optical properties of coastal waters in the Eastern English Channel. Estuar. Coast. Shelf Sci. 72, 201-212.

Werdell, P.J., Franz, B.A., Bailey, S.W., Feldman, G.C., Boss, E., Brando, V.E., Dowell, M. Hirata, T., Lavender, S.J., Lee, Z., Loisel, H., Maritorena, S., Mélin, F., Moore, T.S. Smyth, T.J., Antoine, D., Devred, E., Fanton d'Andon, O.H., Mangin, A., 2013. Generalized ocean color inversion model for retrieving marine inherent optical properties. Appl. Opt. 52, 2019-2037.
Zapata, M., Rodriguez, F., Garrido, J.L., 2000. Separation of chlorophylls and carotenoids from marine phytoplankton: a new HPLC method using a reversed phase C8 column and pyridine-containing mobile phases. Mar. Ecol. Prog. Ser. 195, 29-45.

Zibordi, G., Melin, F., Berthon, J.F., 2006a. Comparison of SeaWiFS, MODIS and MERIS radiometric products at a coastal site. Geophys. Res. Lett. 33.

Zibordi, G., Strombeck, N., Melin, F., Berthon, J.F., 2006b. Tower-based radiometric observations at a coastal site in the Baltic proper. Estuar. Coast. Shelf Sci. 69, 649-654.

Zibordi, G, Berthon, JF, Melin, F, D'Alimonte, D, Kaitala, S, 2009a Validation of satellite ocean color primary products at optically complex coastal sites: Northern Adriatic Sea, Northern Baltic Proper and Gulf of Finland. Remote Sens. Environ. 113, 2574-2591.

Zibordi, G., Holben, B., Slutsker, I., Giles, D., D'Alimonte, D., Melin, F., Berthon, J.F., Vandemark, D., Feng, H., Schuster, G., Fabbri, B.E., Kaitala, S., Seppala, J., 2009b. AERONET-OC: a network for the validation of ocean color primary products. J. Atmos. Ocean. Technol. 26, 1634-1651. 